\title{
CHEK2 Germline Variants in Cancer Predisposition: Stalemate Rather than Checkmate
}

\author{
Lenka Stolarova $^{1,2}$, Petra Kleiblova ${ }^{3}$ (D), Marketa Janatova ${ }^{1}$, Jana Soukupova ${ }^{1}$, \\ Petra Zemankova ${ }^{1}$, Libor Macurek ${ }^{2}$ iD and Zdenek Kleibl ${ }^{1, *(\mathbb{D})}$ \\ 1 Institute of Biochemistry and Experimental Oncology, First Faculty of Medicine, Charles University, \\ 12800 Prague, Czech Republic; lenka.stolarova@lf1.cuni.cz (L.S.); Marketa.Janatova@lf1.cuni.cz (M.J.); \\ Jana.Soukupova@lf1.cuni.cz (J.S.); Petra.Zemankova@lf1.cuni.cz (P.Z.) \\ 2 Laboratory of Cancer Cell Biology, Institute of Molecular Genetics of the Czech Academy of Sciences, \\ 14220 Prague, Czech Republic; libor.macurek@img.cas.cz \\ 3 Institute of Biology and Medical Genetics, First Faculty of Medicine, Charles University and General \\ University Hospital in Prague, 12800 Prague, Czech Republic; pekleje@lf1.cuni.cz \\ * Correspondence: zdekleje@lf1.cuni.cz; Tel.: +420-22496-745
}

Received: 15 November 2020; Accepted: 10 December 2020; Published: 12 December 2020

\begin{abstract}
Germline alterations in many genes coding for proteins regulating DNA repair and DNA damage response (DDR) to DNA double-strand breaks (DDSB) have been recognized as pathogenic factors in hereditary cancer predisposition. The ATM-CHEK2-p53 axis has been documented as a backbone for DDR and hypothesized as a barrier against cancer initiation. However, although CHK2 kinase coded by the CHEK2 gene expedites the DDR signal, its function in activation of p53-dependent cell cycle arrest is dispensable. CHEK2 mutations rank among the most frequent germline alterations revealed by germline genetic testing for various hereditary cancer predispositions, but their interpretation is not trivial. From the perspective of interpretation of germline CHEK2 variants, we review the current knowledge related to the structure of the CHEK2 gene, the function of CHK2 kinase, and the clinical significance of CHEK2 germline mutations in patients with hereditary breast, prostate, kidney, thyroid, and colon cancers.
\end{abstract}

Keywords: checkpoint kinase 2; CHK2; CHEK2; KAP1; WIP1; germline mutation; hereditary cancer; breast cancer; prostate cancer; renal cancer; thyroid cancer; colorectal cancer

\section{Introduction}

The accumulation of DNA mutations during the continually increasing human life span contributes to rising cancer prevalence worldwide [1]. Cancers are now the first or second leading cause(s) of premature death in individuals between 30 and 69 years in 91 countries of the world [2]. DNA alterations with increased cancer-promoting potentials affect tumor suppressor genes participating in DNA damage repair (DDR) and regulating cell cycle checkpoints [3,4]. Moreover, uncoupling these two processes may cause sustained proliferation of genetically unstable cells resulting in malignant transformation.

Most cancers (over 90\%) develop as sporadic tumors during life-long acquisition of DNA mutations. In contrast, less than $10 \%$ of cancers forms hereditary tumors that arise as a result of germline mutations in cancer predisposition genes [5]. Typical features-a high overall cancer risk, earlier age at disease onset, and $50 \%$ probability of transmitting the mutation to the offspring together with an accumulation of tumors in affected families-increase the medical importance of hereditary cancers and justify genetic counseling in affected families. Moreover, the share of hereditary tumors is higher in several frequent or highly malignant cancer types, including breast, pancreatic, or ovarian cancers. The identification of a causal mutation not only directs tumor-specific surveillance and preventive strategies but also 
impacts disease prognosis and targeted treatment [6]. In fact, proper identification and surveillance in mutation carriers has the potential to reduce the bulk of cancer-related mortality associated with several solid tumor types [7].

Fast progress in cancer genetics and the introduction of next-generation sequencing (NGS) have revolutionized the diagnostics of hereditary cancers in the last decade [8,9]. An analysis of individuals at risk using panels of cancer predisposition genes outperforms previous gene-by-gene analyses [10]. The availability of an easy and economically affordable panel NGS analysis together with the widening of testing criteria have brought high volumes of data. Germline variants found in cancer patients not only have confirmed the clinical utility of pathogenic mutations in high-penetrant "first wave" (including BRCA1, BRCA2, MLH1, and MSH2) and "second wave" (PALB2, RAD51C, and $R A D 51 D$ ) genes predisposing to common cancers but also have identified dozens of variants with unknown clinical significance (VUS) and variants of the "second wave" moderate penetrance genes (including ATM or CHEK2) [7,11]. While all cancer predisposition genes are now equal from the perspective of germline testing, the clinical utility of several genes (including CHEK2) varies in a broad interval delimited by their penetrance and population-specific prevalence [12]. The determination of penetrance requires careful assessment in the families of mutation carriers and in large populations of cancer patients and corresponding population-specific controls [13]. Moreover, the classification of germline variants and convincing identification of pathogenic mutations are demanding for most cancer predisposition genes.

In this review, we focus on the CHEK2 gene coding checkpoint kinase 2 protein (CHK2), which was initially recognized as an effector kinase in the ATM-CHK2-p53 pathway in DDR, especially in response to DNA double-strand breaks (DDSB) [14-16]. The competence of the ATM-CHK2-p53 signaling cascade has been hypothesized as a barrier preventing early tumorigenesis [17], inducing cell cycle blockade, apoptosis, or senescence in transformed cells [18]. While initial studies associated CHEK2 germline mutations with a moderate breast cancer risk, later ones identified a much wider portfolio of cancer types in CHEK2 mutation carriers $[19,20]$. Routine genetic testing of CHEK2 is now included in diagnostic NGS panels targeting various hereditary cancers, and CHEK2 ranks among genes with the highest frequency of germline mutations. However, the presence of many variants of unknown significance (VUS) with a specific population prevalence prevents precise assessment of the risk associated with particular tumor types in CHEK2 mutation carriers [21,22]. Thus, finding a CHEK2 germline variant is sometimes perceived as a hindrance to a conclusive genetic interpretation rather than a gain for the clinical management of carriers. With this in mind, we have also reviewed the clinical importance of germline CHEK2 mutations in patients with breast, prostate, kidney, papillary thyroid, and colorectal cancers.

\section{Structure and Function of CHK2 Kinase}

Human CHK2 kinase was identified in 1998 by Matsuoka et al. based on its homology to yeast checkpoint kinases Rad53 (in Saccharomyces cerevisiae) and Cds1 (in Schizosaccharomyces pombe). This pioneering work and subsequent papers from other laboratories were published with a short delay placed CHK2 downstream of ATM activation in DDR [23-25]. CHK2 kinase is widely expressed in proliferating, renewing cell populations but not in resting or terminally differentiated cells [26].

\subsection{The CHEK2 Gene}

Tominaga and colleagues [27] localized the CHEK2 gene to human chromosome 22 (22q12.1), where it spans $54 \mathrm{~kb}$ (chr22: 28,687,743-28,742,422; reverse strand; GRCh38). The most expressed transcription variant 1 (NM_007194/ENST00000404276.6) codes for an mRNA consisting of 15 exons with the translation start localized in exon 2 . The relevance of alternative splicing variants remains unclear, but their proportion increases in tumor tissues [28]. Putative transcription factor binding sites (including SP1, CCAAT box, C/EBP, AP1, and E2F) were identified in the CHEK2 promoter spanning the 268-bp region upstream of the transcription start site [29]. CpG islands identified in the 
$5^{\prime}$ region include a distal (and rarely methylated) CpG island (located -6000 to -8000 from ATG) and a proximal (heavily methylated) CpG island (located -300 to -600 from ATG) [30]. The 3' portion of the CHEK2 gene comprising exons 10-14 is duplicated with $>90 \%$ homology in the human genome (on chromosomes 2, 7, 10, 13, 15, 16, 22, X, and $\mathrm{Y}$ ) as non-expressed pseudogenes [31]. Munch and colleagues [32] performed a phylogenetic analysis of a CHEK2 duplicon in anthropoids, indicating a burst of gene duplication in African great apes and humans.

\subsection{Structure of CHK2 Kinase Protein}

The translation product of the dominant splicing variant consists of 543 amino acids forming the $65 \mathrm{kDa}$ protein. CHK2 comprises three conserved functional domains including a SQ/TQ cluster domain (SCD) at the N-terminus, a forkhead-associated (FHA) domain, and a kinase domain (KD) at the C-terminus [33]. Crystallographic studies have unveiled a nearly complete CHK2 kinase structure in its monomeric and homodimeric forms with the exception of the SCD, extreme C-terminal parts, and several disordered regions, including activation loops (Figure 1) [34-36].

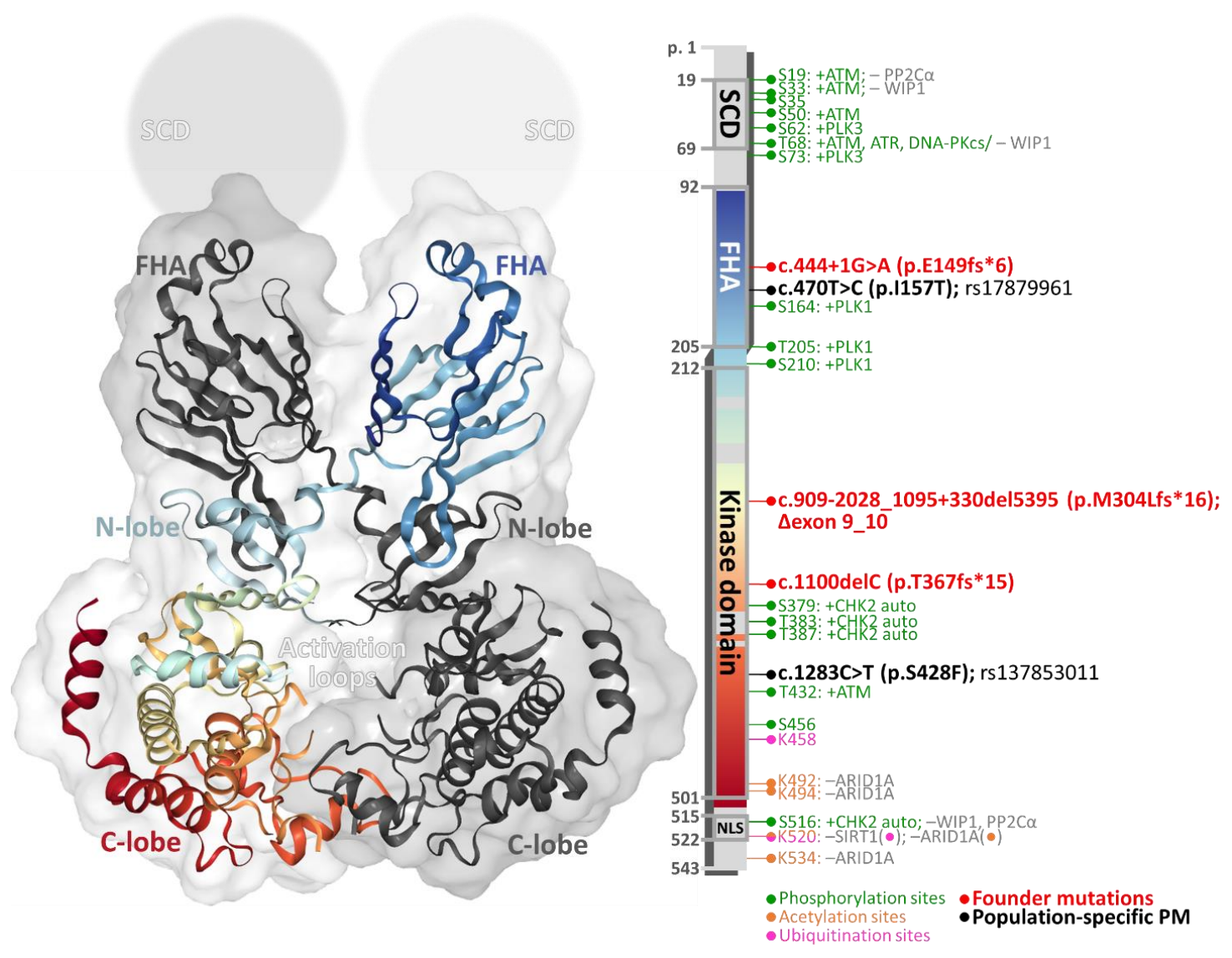

Figure 1. The structure of a CHK2 dimer (left; www.rscb.org/structure/3I6W) consists of intertwined monomers (one subunit is colored in gray, and the second subunit is colored in gradient from the $\mathrm{N}$ - to C-terminus; missing parts of 3D structures are colored in gray). The same color-coding of the bar (right) indicates the positions of conserved domains (boundaries reflect the crystallographic analysis by Cai et al. [35]). Lollipops depict known sites of covalent modifications, founder mutations, and variants.

The SCD (residues 19-69) is characterized by seven pairs of serine-glutamine or threonine-glutamine (SQ/TQ) residues phosphorylated by ATM and other kinases [37,38]. It contains the T68 residue important for CHK2 activation; however, the entire SCD (51 amino acids) consists of $22 \times \mathrm{S}$ and $5 \times \mathrm{T}$ residues representing potential targets for other $\mathrm{S} / \mathrm{T}$ protein kinases. The FHA domain 
(residues 92-205) is arranged in an 11-stranded $\beta$ sandwich and mediates phosphorylation-dependent protein-protein interactions of CHK2 [34]. A seven-residue linker (residues 206-212) connects FHA and the kinase domain (KD). Almost half of the protein sequence comprises a serine-threonine KD (residues 212-501) consisting of two lobes forming an ATP-binding site at the cleft between them. The N-terminal lobe (residues 213-305) is formed mainly by $\beta$-sheet structures and contains a conserved E273 important for catalysis, while the larger C-terminal lobe (306-501) is mostly $\alpha$-helical. The activation loop (residues 371-391) contains several activating phosphorylation sites (T383 and T387) that participate in substrate binding [35]. The nuclear localization signal (NLS) at the C-terminus is recognized by karyopherin- $\alpha 2$ (KPNA2) importing the CHK2 molecule into the nucleus [39].

\subsection{Regulation of CHK2 Kinase Activity}

Extensive covalent modifications of amino acid residues (phosphorylation, ubiquitination, and acetylation) and noncovalent interactions (homodimerization and phosphoprotein-protein interactions) influence the catalytic activity, substrate specificity, intracellular trafficking, and the half-life of CHK2 kinase.

\subsubsection{Phosphorylation}

In the absence of DNA damage stimuli, CHK2 kinase resides in its monomeric inactive form. Upon DNA damage, ATM phosphorylates T68 [37] in the SCD of CHK2, promoting its transient homodimerization. ATM phosphorylation at the T68 priming site is important for full CHK2 activity in cells; however, CHK2 overexpression in bacteria or mammalian cells promotes dimerization and activation independently of ATM or ionizing radiation (IR) [40]. The exploration of CHK2 phosphorylation kinetics demonstrated that T68 phosphorylation occurs 3 min after neocarzinostatin treatment in HCT116 cells, followed by phosphorylation on S19 and S33/35 [38]. In addition, phosphorylation of other residues (S50 and T432) remains unclear [41,42]. Other candidate phosphorylation sites (S120, S260, T225, S379, and S435) were identified in recombinant CHK2 expressed in bacteria and insect cells expression systems using mass spectrophotometry, but their importance is largely unknown [43].

The process of CHK2 kinase activation includes the formation of a transient dimer through reciprocal FHA-KD and FHA-FHA interactions. The I157 residue resides in the center between these interfaces associating intramolecularly with the N-lobe in the KD [35]. The domain-exchanged, intertwined CHK2 homodimer promotes kinase activation by trans-autophosphorylation [35]. Wedged CHK2 molecules trans-phosphorylate T383 and T387 residues in activation loops exchanged between protomers (Figure 1), leading in turn to a disruption of homodimer conformation and release of the two catalytically active CHK2 monomers [34-36,44]. A description of another phosphoserine residue, S516, suggested that activating autophosphorylation of CHK2 can occur in cis (S516) and in trans (T383/387) depending on CHK2 dimerization [40,45]. The phosphorylation of CHK2 T68 has been frequently used as a marker of ATM activation [46], but T68 could be phosphorylated also by ATR in vitro [37] and by the DNA-dependent protein kinase catalytic subunit (PRKDC, alias DNA-PKcs) during mitosis [47]. Other CHK2 phosphorylation sites have been described as the targets of other kinases including polo-like kinase 3 (PLK3) [48,49] or PLK1 [50,51]. PLK3 phosphorylated S62 and S73 in vitro and was proposed to facilitate subsequent phosphorylation on T68 by ATM; however, this possibility has recently been challenged when no impact of PLK3 on checkpoint activation was found [48]. PLK1 in a complex with TP53-binding protein 1 (53BP1) phosphorylates CHK2 on S164, T205, and S210 to prevent its activation in mitosis, with S164 phosphorylation showing the greatest effect. Moreover, a co-localization of CHK2 with PLK1 has been observed during mitosis at centrosomes [52].

\subsubsection{Dephosphorylation}

The activation of CHK2 in DDR is antagonized by its dephosphorylation by protein phosphatases, including WIP1 phosphatase (protein phosphatase Mg/Mn-dependent 1D; PPM1D) [53-55]. 
Human WIP1 belongs to a protein phosphatase type $2 \mathrm{C}$ family and is a homologue of Ptc2 and Ptc3, which regulate Rad53 in yeast [40,56]. WIP1 efficiently dephosphorylates residues at SQ/TQ sites in the CHK2 SCD, including T68 in a cell culture model; however, WIP1 is unable to dephosphorylate phosphorylated T387 in the activation loop [53]. It has been proposed that, under physiological conditions, this WIP1 activity participates in checkpoint recovery rather than in an inhibition of ATM/ATR-mediated response following DNA damage. It seems that fully active CHK2 kinase phosphorylated on residues in the activation loop is less sensitive to WIP1 dephosphorylation activity. Phosphorylated S516 is more accessible for dephosphorylation by other phosphatases, including PP2C $\alpha$ [57]. Carlessi and colleagues [58] identified basal CHK2 phosphorylation (including T68) by tonic ATM signaling in undamaged cells and its counteraction by WIP1, PP2A, and PP1. The authors proposed that the activities of these phosphatases maintain the basal state of the ATM/CHK2 regulatory circuit. A recent study of clonal hematopoiesis in cancer patients treated by radiation, platinum, or topoisomerase II inhibitors found that preferentially selected somatic mutations affect all members of this circuit (ATM, CHEK2, PPM1D, and TP53) and increase the risk of therapy-related myeloid neoplasm development [59].

\subsubsection{Ubiquitination}

CHK2 turnover is regulated by ubiquitin-mediated proteasomal degradation. Several E3 ubiquitin-protein ligases targeting CHK2 have been described. Ubiquitination catalyzed by the PIRH2 E3 ubiquitin-protein ligase (p53-induced protein with a RING-H2 domain) requires dephosphorylation of 5456 in the CHK2 KD [60] and the presence of MDM2 (mouse double minute 2 homolog), an E3 ubiquitin-protein ligase, and P/CAF (p300/CBP-associated factor, known also as lysine acetyltransferase 2B; KAT2B), which was found to have an intrinsic E3 ligase activity [42,61]. Thus, phosphorylation at S456 increases CHK2 stability after DNA damage. In contrast, ubiquitination of CHK2 by seven in absentia homolog 2 (SIAH2) is independent of S456 phosphorylation and has been proposed as a mechanism regulating CHK2 basal turnover [62]. Ubiquitination of CHK2 catalyzed by the E3 ubiquitin-protein ligase complex containing Cullin 1 (CUL1) in response to DNA damage depends also on the autophosphorylation of S379 [63]. However, CUL1-mediated ubiquitination does not affect CHK2 stability. It has rather been proposed to contribute to CHK2-mediated apoptosis in U2OS cells in response to ionizing radiation. CHK2 has been identified in complexes targeted to DNA damage sites with a CHK2-interaction partner and adaptor protein MDC1 (mediator of DNA damage checkpoint protein 1) and with E3 ubiquitin-protein ligase RNF8; however, it has not been determined when CHK2 is ubiquitinated [63]. Recently, Wand and colleagues [64] described that ARID1A (AT-rich interactive domain-containing protein 1A), a component of SWI/SNF chromatin remodeling complexes, targets CHK2 for polyubiquitination at lysine residues K492, K494, K520, and K534. Thus, a loss of ARID1A by somatic mutations (ranking among the most frequent somatic alterations in various tumors) increases the CHK2 level.

Ubiquitination is opposed by deubiquitinases. Among them, USP28 (ubiquitin-specific peptidase 28) and USP39 have been evidenced to deubiquitinate CHK2, with an apparent impact on CHK2 upregulation upon IR or cisplatin-induced DNA damage [65,66].

\subsubsection{Acetylation}

Although acetylases modifying CHK2 by acetylation are largely unknown, several reports have described not only CHK2 deacetylation catalyzed by NAD+-dependent histone deacetylase SIRT1 targeting histones but also non-histone proteins implicated in the regulation of many physiological and pathological processes, including DDR and tumorigenesis [67]. A recent study showed that SIRT1 directly deacetylates K520 in CHK2, suppressing its phosphorylation, dimerization, and thus activation. Moreover, this study provides evidence that Chk2 hyperactivity in Sirt1-/- mice is responsible for embryonic lethality that could be rescued by Chek 2 co-deletion. 
In conclusion, CHK2 covalent modifications affect its catalytic activity, turnover, and targeting. However, it is still not certain how covalent modifications influence CHK2 substrate specificity and direct CHK2 functions depending on the cell cycle phase.

\subsection{CHK2 Substrates and Its Effector Pathways}

Once activated, CHK2 phosphorylates many intracellular targets carrying a consensus motif containing a hydrophobic amino acid $\left(\mathrm{B}^{\alpha}\right)$ at position -5 and arginine $(\mathrm{R})$ residue at position -3 : $\mathrm{B}^{\alpha}-\mathrm{X}-\mathrm{R}-\mathrm{X}-\mathrm{X}-\mathrm{S} / \mathrm{T}$ [68]. Activated CHK2 kinase then participates in the regulation of many intracellular pathways that were comprehensively reviewed by Zannini and colleagues [69]. Our review summarizes CHK2 activities related to the process of tumorigenesis.

\subsubsection{CHK2 in the Regulation of the Cell Cycle, Apoptosis, and Senescence}

CHK2 is traditionally portrayed as an effector kinase in the ATM-CHK2-p53 pathway mediating response to DDSB (Figure 2) [14-16]. The double-strand DNA breaks, representing highly toxic events in proliferated cells, are recognized by the MRE11-RAD50-NBN1 (MRN) complex recruiting ataxia telangiectasia-mutated (ATM) kinase into the site of DNA damage [70]. This, in turn, activates ATM, a master regulator of the DDR [71]. ATM phosphorylates CHK2 and other proteins orchestrating DDSB repair and DDR. CHK2 overlaps some ATM targets, amplifies an ATM-triggered signal, and increases the DDR regulation fidelity. A parallel DDR pathway, ATR-CHK1-p53 exploiting CHK1 kinase, is activated mainly by the presence of long stretches of single-stranded (ss)DNA or DNA crosslinks, and it targets several overlapping substrates [72,73].

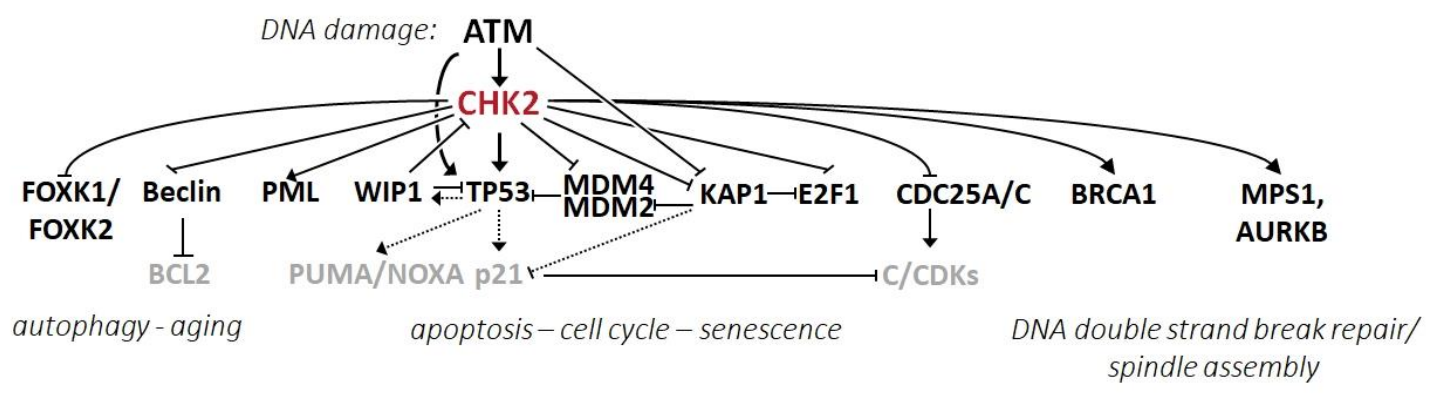

Figure 2. In the presence of DNA damage, especially in the presence of DNA double-strand breaks, sensor protein complexes (not shown) activate the apical kinase ATM phosphorylating CHK2. As an effector kinase, CHK2 phosphorylates numerous substrates (described in the text) participating in critical pathways deregulated in the process of tumorigenesis.

One of the first reported CHK2 targets is the tumor suppressor protein p53. Activated ATM phosphorylates p53 at S15, increasing its stability and activation [74]. Simultaneous phosphorylation of MDM2 disrupts MDM2-p53 interaction and allows p53 stabilization. CHK2 acts on p53 in a similar fashion and phosphorylates p53 at S20, contributing to p53-dependent cell cycle arrest in the G1 phase [75]. Besides, CHK2 phosphorylates MDM4 on S342 and S367 in vivo [76], possibly impacting the transcriptional activity of p53. p53 transactivation targets include the CDKN1A gene, coding the inhibitor of cyclin/CDK complexes p21 ${ }^{\mathrm{CIP} 1 / \mathrm{WAF} 1}$ and the GADD45A (growth arrest and DNA damage inducible $\alpha$ ) gene coding a versatile stress sensor [77-79]. Although CHK2 was initially implicated in the induction of a p53-dependent checkpoint, more recent studies have suggested that the endogenous level of CHK2 does not cause G1 arrest and that the observed checkpoint activation may be an artefact attributable to CHK2 protein overexpression [80]. In agreement with this, no checkpoint defect was observed in HCT116 cells lacking CHK2 and thus the impact of CHK2 on the p53 pathway remains unclear $[33,81]$.

The expressions of p21 and GADD45a are also inhibited by the KRAB (Kruppel-Associated Box Domain)-Associated Protein 1 (KAP1) transcription co-repressor targeting the KRAB-zinc finger 
protein superfamily of transcription factors [82]. Upon DNA damage, KAP1 is phosphorylated by ATM and CHK2 (or CHK1) at S824 and S473, respectively [83]. While CHK2 phosphorylates KAP1 dominantly in an etoposide- or ionizing radiation-induced stress response, CHK1 targets the same S473 residue in response to UV radiation. KAP1 S473 phosphorylation relieves its transcriptional repression, which results in increased p21 and GADD45 expressions at the G2/M checkpoint [84]. However, KAP1 S473 also provides a binding site for the E2F1 transcription factor involved in the cell cycle and apoptosis. Increased interaction between KAP1 phosphorylated at S473 and E2F1 decreases the expression of a subset of proapoptotic genes and apoptosis [83]. Besides, CHK2 directly phosphorylates E2F1 at S364, which results in increased E2F1 protein stability and transcriptional activity towards p53-independent apoptosis [85]. Thus, CHK2-activated KAP1 phosphorylation may counteract CHK2-induced E2F1 activity in DDR as a negative regulatory feedback mechanism. Targeting this regulatory network by combination chemotherapy using etoposide and inhibitors of KAP1-S473 phosphorylation may potentiate the cytotoxic effect of chemotherapy [83].

CHK2 has been shown to phosphorylate CDC25 phosphatases, a family of homologous dual-specific enzymes dephosphorylating inhibitory phosphothreonine or phosphotyrosine residues on cyclin-dependent kinases (CDKs) stimulating transition through the cell cycle [86]. The inhibition of CDC25 phosphatases by phosphorylation ensures rapid but transient checkpoint activation, while the activation of p53 is required for longer cell cycle arrest, the induction of senescence, or apoptosis [87]. A CHK2-mediated phosphorylation of CDC25A phosphatase at S123 inhibits dephosphorylation of the cyclin-dependent kinase 2 (CDK2)-cyclin E complex, halting the cell cycle before entry into the $\mathrm{S}$ phase [14]. Moreover, CHK2 also phosphorylates CDC25C phosphatase at S216, stimulating an interaction of CDC25C with 14-3-3 proteins. The interaction with 14-3-3 proteins displaces CDC25C from binding and the dephosphorylation of a CDK1-cyclin B complex, required for its activation before mitotic entry $[16,88]$.

CHK2 phosphorylates S117 of the promyelocytic leukemia protein (PML, a tumor suppressor involved in multiple apoptotic pathways) and increases its activity in the induction of $\gamma$-radiation-induced apoptosis [89]. In contrast, a fusion protein of PML with retinoic acid receptor $\alpha$ (PML-RAR $\alpha)$, resulting from frequent translocation in acute promyelocytic leukemia $(\mathrm{t} 15 ; 17)$, suppresses CHK2 and inhibits its autophosphorylation [90,91].

\subsubsection{CHK2 in the Regulation of DNA Repair and Mitotic Spindle}

In response to ionizing radiation, $\mathrm{CHK} 2$ phosphorylates breast cancer susceptibility protein 1 (BRCA1) at S988, which is believed to modulate the BRCA1 function in DNA repairs towards a homologous recombination (HR) repair instead of non-homologous end joining (NHEJ) [92,93]. Alongside its function in HR, BRCA1 (and other proteins identified as regulators or executors in DDR) has been implicated in mitotic spindle assembly [94]. In case of spindle damage, BRCA1 gets phosphorylated at $\mathrm{S} 988$ by $\mathrm{CHK} 2$, which leads to protein accumulation and to inhibition of the microtubule-nucleating activity of the centrosome [95-97]. The activity of CHK2 in centrosome regulation includes also the phosphorylation of $\mathrm{S} / \mathrm{T}$ residues in other regulators, including T288 in the dual specificity protein kinase TTK (alias MPS1), S331 in aurora kinase B (AURKB), or S507 in myosin phosphatase targeting subunit 1 (MYPT1) [94,98]. Cells and organisms lacking CHK2 are viable and fertile, suggesting that its function in mitosis is not essential, and thus, the precise impact of CHK2 on cell division remains to be elucidated.

\subsubsection{CHK2 in the Regulation of Autophagy and Aging}

CHK2 kinase was also reported to be involved in other processes apart from DDR or cell cycle regulation. In response to oxidative stress, CHK2 has been linked to cell protection via autophagy. High levels of reactive oxygen species (ROS) and hypoxia were reported to trigger the ATM-CHK2 axis and the phosphorylation of Beclin 1 [99]. Beclin 1, coded by the tumor suppressor gene BECN1, is an essential regulator of autophagy, and its phosphorylation at $\mathrm{S} 90 / \mathrm{S} 93$ by $\mathrm{CHK} 2$ has been shown to 
disrupt the formation of Beclin 1 (BCL2 autophagy-regulatory complex), reducing ROS production by the autophagy of damaged mitochondria. Thus, the ATM-CHK2-BECN1 autophagy axis may serve as a physiological pathway preventing tissue damage following ischemia [99]. In addition, CHK2 phosphorylates Forkhead transcription factors FOXK1 and FOXK2, which act as transcriptional repressors of autophagy-related genes [100]. CHK2-mediated FOXK phosphorylation induces their binding to 14-3-3 proteins, which, in turn, traps FOXK in the cytoplasm and induces autophagy following DNA damage.

\subsubsection{CHK2 in the Regulation of Other Intracellular Pathways}

While CHK2 kinase was characterized as a downstream kinase transmitting DDR signal onto effectors over 20 years ago, new functions of CHK2 and the ATM-CHK2 axis have been identified and reviewed by Zannini and colleagues [69]. These "non-canonical" CHK2 activities include stem cell maintenance, regulation of the intracellular response to a viral infection, or the participation of circadian clock regulation.

Despite substantial progress, it should be noted that many canonical as well as novel CHK2 functions have been studied dominantly in model systems involving tumor cell lines. However, little is still known about the real demand for CHK2 functions in particular tissues under physiological and pathological conditions. Animal experiments with Chek2 knockout $\left(\mathrm{Chk}^{-\digamma_{-}^{-}}\right)$mice demonstrated that $\mathrm{Chk} 2^{-/-}$mice are viable and fertile, developing a slightly increased tumor incidence with a long latency, and that they are more radioresistant compared with wild type Chk2 mice [101]. This indicates that Chk2 activity is redundant and may be compensated for example by Chk1 kinase sharing overlapping substrates. This hypothesis has supported subsequent experiments demonstrating that double mutant $\mathrm{Chk1}^{+/-} / \mathrm{Chk} 2^{-/-}$and $\mathrm{Chk1} 1^{+/-} / \mathrm{Chk2}^{+/-}$mice have a progressive cancer-prone phenotype [102].

Interestingly, the prevalence of germline CHEK2 mutations in cancer patients outnumbers that in CHEK1 by the order of magnitude. The same is true also for somatic mutations in these two kinases. Individuals carrying bi-allelic CHEK2 mutations have a normal phenotype; however, they carry an increased cancer risk in comparison with heterozygotes and noncarriers [103,104]. However, the cell-type specific demand for CHK2 activation in human tissues is largely unknown. Recently, van Jaarsveld and colleagues [105] compared CHK2 activation in primary breast and lung cells, describing a significantly higher CHK2 activity in breast than in lung primary cells. These observations can further stimulate investigations revealing tissue-specific cancer development in CHEK2 mutation carriers.

\section{Germline CHEK2 Variants}

Germline mutations in the CHEK2 gene and their association with cancer development were originally described in 1999 (a year after its discovery) by Bell and colleagues [19], who identified the most studied population-specific CHEK2 variants c.1100delC and p.I157T in predominantly breast cancer patients from p53-wild type Li-Fraumeni syndrome (LFS) and LFS-like (LFL) families. The observation that $C H E K 2$ mutations associate with these clinically severe syndromes alongside the functional activity of CHK2 kinase in DDR attracted huge interest, and for a while, CHEK2 was a candidate for the putative "BRCA3" gene. The first functional analysis revealed that c.1100delC completely abrogates CHK2 kinase activity [106]. However, the association between germline CHEK2 mutations and LFS/LFL was disputed soon afterwards [31,107-111]. Moreover, the CHEK2 consortium (comprising laboratories from the UK, the Netherlands, the USA, and Germany) identified only an incomplete segregation of c.1100delC with cancer phenotypes in breast cancer families [112] and found a high prevalence of heterozygous c.1100delC carriers, exceeding $1 \%$ in Netherlands and UK controls. The high prevalence of c.1100delC in northern Europe was also confirmed by a study from Finland [110]. Although these early studies found that the frequency of c.1100delC mutations was enriched among breast cancer patients with early and/or double primary tumors and in multiple cancer families, an incomplete penetrance of c.1100delC in cancer families and a high prevalence of the 
variant in controls substantially distorted $C H E K 2^{\prime}$ s credit as a clinically considerable predisposing gene. In contrast, Cybulski and colleagues [20] analyzed two founder truncations, c.1100delC and c.444+1G $>$ A, and the p.I157T missense variant in a large group of Polish patients and characterized CHEK2 as a multi-organ cancer susceptibility gene. Their analysis of 4008 cases with 13 tumor types and 4000 controls found a moderately increased risk of breast, prostate, and thyroid cancer in carriers of truncating CHEK2 mutations and an increased risk of breast, colon, kidney, prostate, and thyroid cancer for the carriers of p.I157T. Since then, a growing body of evidence has suggested that germline CHEK2 variants deserve interest from the perspective of clinical oncology as their carriers face an increased risk of various cancer types that display some specific clinicopathological characteristics.

Unfortunately, the identification of c.1100delC (and a few other variants) as a CHEK2 founder mutation (Figure 1) limited CHEK2 analyses dominantly to these variants in most pre-NGS studies. Aloraifi and colleagues performed a meta-analysis of protein-truncating variants in moderate-risk breast cancer genes in 2015 and cited only 12 out of 54 published CHEK2 analyses (22\%) that had performed full gene scanning [113]. Recently, a spectrum of CHEK2 pathogenic/likely pathogenic variants identified in 2508 carriers analyzed by GeneDx in the USA was published by Sutcliffe and colleagues [114]. They showed that nearly $95 \%$ of all carriers have some of the 18 variants detected more than 10 times, while the remaining approximately $5 \%$ of individuals carried one of the 101 rare germline variants including 17 large intragenic rearrangements. About $73 \%$ of individuals carried some of the five most frequent founder variants (including p.I157T and p.S428F). A full gene analysis was largely introduced with NGS panels. However, the identification of copy number variations (CNV), which represent a substantial fraction of CHEK2 germline mutations (exon 9-10 deletions (denoted also 5395del) in Slavic populations [115] and US patients [114] and exons 2-3 and 6 in Greece [116]), is still not a golden standard. Besides, pseudogene sequences homologous to exons 10-14 limited analyses in early NGS studies $[117,118]$. Thus, our understanding of CHEK2's contribution to cancer predisposition is incomplete as founder mutations vary among different ethnics and non-founder alterations account for over $25 \%$ of $C H E K 2$ pathogenic variants.

The bottleneck limiting the clinical outcomes of NGS analyses is rare VUS [119]. They currently account for 1228 out of 2195 (55.9\%) germline CHEK2 variants reported in ClinVar (https://www. ncbi.nlm.nih.gov/clinvar/?term=chek2; accessed 07-11-2020). As the majority of the CHEK2 coding sequence comprises established domains, the prioritization of CHEK2 VUS based on their presence in conserved regions is useless. Some studies have aimed to perform functional analyses challenging the catalytic activity; the activities of putative substrates; protein stability; and dimerization or localization of investigated CHK2 isoforms using in vitro [120,121], bacterial [122], yeast [21,123-125], or human cell models [115]. Besides a handful of exceptions [21,115,123], however, the published studies have only analyzed a single or a few variants, and their results were mutually concordant only in part. Therefore, a systematic analysis of CHEK2 VUS is highly desirable as rare missense variants or small in-frame deletions are frequent and they may represent $25-50 \%$ of all germline CHEK2 alterations $[114,115,122,126,127]$.

\subsection{Ethnic and Geographical Differences in CHEK2 Mutation Frequency}

The prevalence of germline CHEK2 variants substantially varies among different populations and ethnics. These differences can be demonstrated on multiethnic studies utilizing an identical approach. Kurian and colleagues collected data from germline testing in 5900 breast and 937 ovarian cancer patients from California and Georgia [128]. They found that pathogenic CHEK2 variants were the third most frequent germline alterations in both cancers (following $B R C A 1 / B R C A 2$ variants); however, CHEK2 significantly prevailed in whites over blacks in both breast cancer $(2.3 \%$ vs. $0.15 \%)$ and ovarian cancer $(1.3 \%$ vs. $0 \%)$. An analysis by Caswell-Jin et al. also identified significant differences in the frequency of pathogenic CHEK2 mutations between whites and non-whites ( $3.8 \%$ vs. $1.0 \% ; p=0.002)$ tested for hereditary cancer risk [22]. 
Although CHEK2 has the highest mutation prevalence among Caucasian individuals of European descent, the spectrum and frequency of founder as well as non-founder mutations vary among particular European populations. The frequency of the European founder mutation c.1100delC declines from the north to the south [129], with carrier frequency in the general population close to $1 \%$ in the UK and the Netherlands but very rare in the Mediterranean region [130-132]. The most frequent European CHEK2 variant, p.I157T, has a population frequency of heterozygous carriers of around 5\% in Poles [20], Latvians [133], Hungarians [134], and Russians [135] and around 2-3\% in Czechs [136], Slovaks [134], and Germans [126]. Interestingly, the p.I157T allele has developed in some populations independently [137]. This high population frequency rules out the possibility that the p.I157T variant could have a higher than low impact on cancer susceptibility; however, an increased risk with odds ratio (OR) approximately 1.5 in p.I157T carriers has been described systematically in case control studies and meta-analyses for breast cancer (Table 1) and other cancer types. Another central European founder mutation, a deletion of exons 9-10, was described by Walsh et al. [138] in patients of Czech and Slovak origins (Figure 1). A high background frequency of this variant in controls was also found in Poland (0.4\%) [139] and Latvia (0.7\%) [140].

The lowest frequency of CHEK2 germline mutations is reported in patients of Asian origin. A panel NGS analysis involving 8085 Chinese breast cancer patients revealed only 18 ( $0.3 \%)$ carriers of pathogenic CHEK2 mutations [141]; eight of them carried the novel founder nonsense mutation c.C417A (p.Y139*) [142]. Only two carriers $(0.24 \%)$ of CHEK2 mutations were identified in a recent analysis of 831 breast cancer patients from Shanghai [143]. Studies of breast and prostate cancer patients from Japan included analyses in control populations that revealed the presence of pathogenic CHEK2 germline mutations in $0.1 \%$ of both female and male noncancer controls [144,145]. 
Table 1. Analyses of the entire CHEK2 coding sequence (separately or as part of panel next-generation sequencing (NGS)) or analyses of specific variant(s) in breast cancer (BC) patients.

\begin{tabular}{|c|c|c|c|c|}
\hline Reference & Population & $\begin{array}{l}\text { P: Patients } \\
\text { C: Controls }\end{array}$ & Analysis * & $\begin{array}{c}\text { Odds Ratio (95\% Confidence Interval); } \\
\text { p-Remark } \\
\text { (Statistically Insignificant in Italics) }\end{array}$ \\
\hline \multicolumn{5}{|c|}{ Female breast cancer } \\
\hline $\begin{array}{c}\text { Fostira } 2020 \\
{[146]}\end{array}$ & GR & $\begin{array}{l}\text { P: } 1382 \text { high-risk BC patients } \\
\text { C: ExAC/FLOSSIES }\end{array}$ & $\begin{array}{c}\text { CHEK2 } \\
\text { (panel NGS) }\end{array}$ & $\begin{array}{c}1.7 \text { (0.98-2.7); } 0.11 \text {-all LoF variants/ExAC } \\
2.6(1.44-4.68) ; 0.003 \text {-all LoF } \\
\text { variants/FLOSSIES } \\
3.8(1.86-7.12) ; 1.2 \times 10^{-3} \text {-missense } \\
\text { deleterious/ExAC } \\
5.9(2.38-14.8) ; 1.2 \times 10^{-4} \text {-missense } \\
\text { deleterious/FLOSSIES }\end{array}$ \\
\hline $\begin{array}{c}\text { Kurian } 2020 \\
\text { [147] }\end{array}$ & $\begin{array}{c}\text { US } \\
\text { (66\% white) }\end{array}$ & $\begin{array}{l}\text { P: 2,195 postmenopausal BC } \\
\text { C: } 2322 \text { age-matched PMC }\end{array}$ & CHEK2 (panel NGS) & $\begin{array}{c}\text { N.D.; } \\
\text { CHEK2 PV found in } 0.59 \% \mathrm{P} \text { and } 0.26 \% \mathrm{C}\end{array}$ \\
\hline $\begin{array}{c}\text { Rogoza-Janiszewska } 2020 \\
{[148]}\end{array}$ & PL & $\begin{array}{l}\text { P. 2,464 BC diagnosed at }<41 \\
\text { C: from Cybulski } 2019\end{array}$ & $\begin{array}{c}\text { c.1100delC; c. } 444+1 G>A ; \\
\text { del5395 }\end{array}$ & $\begin{aligned} & 3.8(2.53-5.58) ;<0.0001-\mathrm{BC} \text { at }<41 \mathrm{y} ; \text { all } \\
& \text { truncations } \\
& 4.6(2.44-8.80) ;<0.0001-\mathrm{BC} \text { at }<31 \mathrm{y} ; \text { all } \\
& \text { truncations }\end{aligned}$ \\
\hline $\begin{array}{c}\text { Kleiblova } 2019 \\
\text { [115] }\end{array}$ & $\mathrm{CZ}$ & $\begin{array}{c}\text { P: } 1526 \text { high-risk female BC } \\
\text { C: } 3360 \text { PMC }\end{array}$ & CHEK2 (panel NGS) & $\begin{array}{c}7.94(3.90-17.47) ; 4.1 \times 10^{-11} \text { —unilat. BC: } \\
\text { truncations } \\
3.90(1.24-13.35) ; 0.009 \text {-unilat. BC: } \\
\text { deleterious missense } \\
8.39 \text { (1.92-28.74); } 0.003 \text {-bilat. BC: } \\
\text { truncations } \\
3.77 \text { (0.08-31.42); } 0.26 \text {-bilat BC: deleterious } \\
\text { missense }\end{array}$ \\
\hline $\begin{array}{c}\text { Cybulski } 2019 \\
{[149]}\end{array}$ & PL & $\begin{array}{c}\text { P: 1,018 hereditary BC } \\
\text { C: } 4346 \text { PMC }\end{array}$ & $\begin{array}{l}\text { c. } 1100 \text { delC } \\
\text { c. } 444+1 G>A \\
\text { del5395 }\end{array}$ & $\begin{array}{c}6.9(3.2-14.7) ;<0.0001 \text {-for c. } 1100 \mathrm{delC} \\
8.4(3.0-23.3) ;<0.0001 \text {-for c. } 444+1 \mathrm{G}>\mathrm{A} \\
6.5(3.2-13.4) ;<0.0001 \text {-for del53957.2 } \\
(4.5-11.6) ;<0.0001 \text {-for all above truncations }\end{array}$ \\
\hline
\end{tabular}


Table 1. Cont.

\begin{tabular}{|c|c|c|c|c|}
\hline Reference & Population & $\begin{array}{l}\text { P: Patients } \\
\text { C: Controls }\end{array}$ & Analysis * & $\begin{array}{c}\text { Odds Ratio (95\% Confidence Interval); } \\
\text { p-Remark } \\
\text { (Statistically Insignificant in Italics) }\end{array}$ \\
\hline $\begin{array}{c}\text { Nurmi } 2019 \\
\text { [150] }\end{array}$ & FI & $\begin{array}{l}\text { P: } 3156 \text { BC } \\
\text { C: } 2089 \text { PMC }\end{array}$ & $\begin{array}{c}\text { c. } 319+2 \mathrm{~T}>\mathrm{A} ; \mathrm{c} .444+1 \mathrm{G}>\mathrm{A} ; \\
\text { c. } 1100 \mathrm{delC}\end{array}$ & $\begin{array}{c}5.40(1.58-18.45) ; 0.007 \text {-for c. } 319+2 \mathrm{~T}>\mathrm{A} \\
\text { unselected BC } \\
6.04(1.65-22.10) ; 0.007 \text {-for c. } 319+2 \mathrm{~T}>\mathrm{A} \\
\text { familial BC }\end{array}$ \\
\hline $\begin{array}{c}\text { Girard } 2019 \\
\text { [151] }\end{array}$ & FR & $\begin{array}{l}\text { P: } 1207 B R C A 1 / 2^{-v e} B C \text { pts } \\
\text { having sister with BC } \\
\text { C: } 1199 \text { non-cancer PMC }\end{array}$ & $\begin{array}{c}\text { CHEK2 } \\
\text { (WES + panel NGS) }\end{array}$ & $\begin{array}{c}3.0(1.9-5.0) ; 1 \times 10^{-5} \text {-any rare variant } \\
5.8(2.0-16.9) ; 0.001 \text { - LoF variants } \\
2.4(1.4-4.3) ; 0.002 \text { - likely-deleterious missense }\end{array}$ \\
\hline $\begin{array}{c}\text { Hauke } 2018 \\
\text { [126] }\end{array}$ & $\mathrm{DE}$ & $\begin{array}{l}\text { P: } 5589 \text { BRCA1/2-ve BC } \\
\text { C: } 2189 \text { non-cancer PMC }\end{array}$ & CHEK2 (panel NGS) & $3.72(1.99-6.94) ;<0.0001$-truncations \\
\hline $\begin{array}{c}\text { Momozawa } 2018 \\
\text { [145] }\end{array}$ & $\mathrm{JP}$ & $\begin{array}{c}\text { P: } 7051 \text { BC } \\
\text { C: } 11,241 \text { PMC }\end{array}$ & CHEK2 (panel NGS) & $3.2(1.6-6.8) ; 3.2 \times 10^{-4}$ \\
\hline $\begin{array}{c}\text { Decker } 2017 \\
\text { [152] }\end{array}$ & UK & $\begin{array}{l}\text { P: } 13,087 \mathrm{BC} \\
\text { C: } 5488 \text { PMC }\end{array}$ & $\begin{array}{c}\text { CHEK2 } \\
\text { (\& } 3 \text { other genes) }\end{array}$ & $\begin{array}{c}3.11(2.15-4.69) ; 5.6 \times 10^{-11} \text { - truncations } \\
1.36(0.99-1.87) ; 0.066 \text {-all rare missense } \\
1.51(1.02-2.24) ; 0.047 \text {-rare missense in any } \\
\text { domain } \\
3.27(1.66-5.83) ; 0.0014 \text {-bilateral BC } \\
3.42(2.33-5.21) ; 1.5 \times 10^{-11} \text { - } \mathrm{ER}^{+\mathrm{ve}} \mathrm{BC} \\
3.98(2.62-6.21) \text {-age at dg }<50 \text { years } \\
3.37(2.24-5.22) \text {-age at dg }=50-60 \text { years } \\
2.12(1.35-3.41) \text { - age at dg }>60 \text { years }\end{array}$ \\
\hline $\begin{array}{c}\text { Slavin } 2017 \\
\text { [153] }\end{array}$ & $\begin{array}{c}\text { US } \\
\text { (80\% white) }\end{array}$ & $\begin{array}{c}\text { P: } 2266 \text { BRCA1/2-ve fam. BC } \\
\text { C: ExAC }\end{array}$ & $\begin{array}{c}\text { CHEK2 } \\
\text { (panel NGS) }\end{array}$ & $1.62(1.03-2.51) ; 0.004$ - truncations \\
\hline $\begin{array}{c}\text { Couch } 2017 \\
\quad[154]\end{array}$ & $\begin{array}{c}\text { US } \\
\text { (white) }\end{array}$ & $\begin{array}{c}\text { P: } 29,090 \mathrm{BC} \\
\text { C: } 25,215 \text { ExAC-NFE }\end{array}$ & $\begin{array}{c}\text { CHEK2 } \\
\text { (panel NGS) }\end{array}$ & $\begin{array}{c}2.31(1.88-2.85) ; 3.04 \times 10^{-17} \text {-c.1100delC } \\
2.26(1.89-2.72) ; 1.75 \times 10^{-20}-\text { PVs (w/o p.I157T, } \\
\text { p.S428F) } \\
1.48(1.31-1.67) ; 1.11 \times 10^{-10} \text { _any var }(\mathrm{w} \\
\text { p.I157T, p.S428F) } \\
1.35(1.1-1.63) ; 0.0002 ; \text { bilateral BC }\end{array}$ \\
\hline
\end{tabular}


Table 1. Cont.

\begin{tabular}{|c|c|c|c|c|}
\hline Reference & Population & $\begin{array}{l}\text { P: Patients } \\
\text { C: Controls }\end{array}$ & Analysis * & $\begin{array}{c}\text { Odds Ratio (95\% Confidence Interval); } \\
\text { p-Remark } \\
\text { (Statistically Insignificant in Italics) }\end{array}$ \\
\hline $\begin{array}{l}\text { Schmidt } 2016 \\
\text { [155] }\end{array}$ & $\mathrm{BCAC}$ & $\begin{array}{l}\text { P: } 44,777 \text { population }+ \\
\text { hospital-based BC } \\
\text { C: } 42,977 \text { PMC }\end{array}$ & c.1100delC & $\begin{array}{c}2.26(1.90-2.69) ; 2.3 \times 10^{-20} \text { _invasive BC } \\
2.55(2.10-3.10) ; 4.9 \times 10^{-21} \mathrm{ER}^{+\mathrm{ve}} \mathrm{BC} \\
1.32(0.93-1.88) ; 0.12-E R^{-v e} B C\end{array}$ \\
\hline Naslund-Koch 2016 [156] & DK & $\begin{array}{l}2442 \text { BC pts } / 86,975 \text { individ. } \\
\text { (longitudinal study) }\end{array}$ & c.1100delC & $2.08(1.51-2.85) ;<0.001$ \\
\hline $\begin{array}{c}\text { Southey } 2016 \\
\text { [157] }\end{array}$ & BCAC & $\begin{array}{c}\text { P: } 42,671 \\
\text { C: } 42,164 \text { PMC }\end{array}$ & $\begin{array}{c}\text { iCOGS array } \\
\text { incl. } 6 \text { rare CHEK2 variants }\end{array}$ & $\begin{array}{l}2.26(1.29-3.95) ; 0.003 \text {-for } p . R 117 \mathrm{G} \\
1.33(1.05-1.67) ; 0.016 \text {-for } p . R 180 \mathrm{C} \\
1.70(0.73-3.93) ; 0.210 \text {-for } p . \mathrm{E} 239 \mathrm{~K} \\
5.06(1.09-23.5) ; 0.017 \text {-for } p . R 346 C \\
1.03(0.62-1.71) ; 0.910 \text {-for } p . D 438 Y\end{array}$ \\
\hline $\begin{array}{l}\text { Liu Y } 2011 \\
\quad[158]\end{array}$ & $\mathrm{CN}$ (Han) & $\begin{array}{l}\text { P: } 118 \text { familial BC } \\
\text { P: } 909 \text { unselected BC } \\
\text { C: } 1228 \text { healthy PMC }\end{array}$ & CHEK2 (dHPLC) for familial BC & 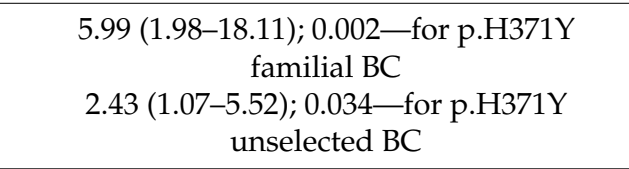 \\
\hline $\begin{array}{c}\text { Cybulski } 2011 \\
\text { [159] }\end{array}$ & PL & $\begin{array}{c}\text { P: } 7494 B R C A 1^{- \text {ve }} \text { BC } \\
\text { C: } 4346 \text { PMC }\end{array}$ & $\begin{array}{c}\text { c.1100delC; c.444+1G>A; } \\
\text { del5395 }\end{array}$ & 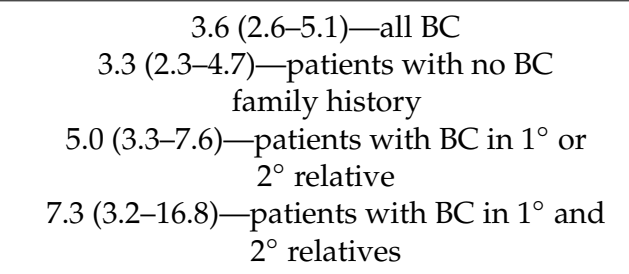 \\
\hline $\begin{array}{c}\text { Desrichard } 2011 \\
\text { [122] }\end{array}$ & FR & $\begin{array}{l}\text { P: } 507 \text { BRCA1/2-ve BC } \\
\text { C: } 513 \text { non-cancer PMC }\end{array}$ & CHEK2 (sequencing) & $\begin{array}{c}4.15(1.38-12.50) ; 0.007 \text {-any variant } \\
5.18(1.49-18.00) ; 0.004 \text { - deleterious } \\
\text { (p.K244R ex) }\end{array}$ \\
\hline $\begin{array}{l}\text { Le Calvez-Kelm } 2011 \\
\text { [160] }\end{array}$ & US/CA/AU & $\begin{array}{c}\text { P: } 1242 \text { BC } \leq 45 y \\
\text { C: } 1109 \text { non-ca PMC female }\end{array}$ & CHEK2 (HRM) & $\begin{array}{c}6.18(1.76-21.8) \text {-truncations/splice mutations } \\
2.20(1.20-4.01) \text {-rare missense }\end{array}$ \\
\hline $\begin{array}{c}\text { Fletcher } 2009 \\
\text { [161] }\end{array}$ & $\begin{array}{l}\mathrm{UK} / \mathrm{FI} / \mathrm{NL} / \\
\mathrm{RU} / \mathrm{DE}\end{array}$ & $\begin{array}{l}\text { P: } 1828 \text { bilateral BC } \\
\text { C: } 7030 \text { PMC }\end{array}$ & c.1100delC & $\begin{array}{c}6.43(4.33-9.53) ;<0.0001 \text { — second primary for } \\
\text { mut. carriers }\end{array}$ \\
\hline
\end{tabular}


Table 1. Cont.

\begin{tabular}{|c|c|c|c|c|}
\hline Reference & Population & $\begin{array}{l}\text { P: Patients } \\
\text { C: Controls }\end{array}$ & Analysis * & $\begin{array}{c}\text { Odds Ratio (95\% Confidence Interval); } \\
\text { p-Remark } \\
\text { (Statistically Insignificant in Italics) }\end{array}$ \\
\hline $\begin{array}{l}\text { Weischer } 2007 \\
\text { [162] }\end{array}$ & DK & $\begin{array}{l}\text { P + C: } 9231 \text { (prospective) } \\
\text { P: } 1101 \text { BC/4665 PMC } \\
\text { (case-control) }\end{array}$ & c.1100delC & $\begin{array}{l}3.2(1.0-9.9) — B C \text { (prospective study) } \\
2.6(1.3-5.4)-B C \text { (case-control study) }\end{array}$ \\
\hline $\begin{array}{c}\text { Cybulski } 2006 \\
{[163]}\end{array}$ & PL & $\begin{array}{c}\text { P: } 3228 \text { BC diagnosed at } \leq 50 \\
\text { C: } 5496 \text { PMC }\end{array}$ & $\begin{array}{l}\text { c. } 1100 \text { delC } \\
\text { c. } 444+1 G>A \\
\text { p.I157T }\end{array}$ & $\begin{array}{c}2.3(1.1-4.8) ; 0.04 \text {-for c. } 1100 \mathrm{delC} \\
2.4(1.4-4.2) ; 0.002 \text {-for c. } 444+1 \mathrm{G}>\mathrm{A} \\
2.4(1.5-3.7) ; 0.0001 \text {-for any truncation } \\
1.4(1.1-1.6) ; 0.002 \text {-for } \mathrm{p} . \mathrm{I} 157 \mathrm{~T}\end{array}$ \\
\hline Chekmariova 2006 [164] & RU & $\begin{array}{l}\text { P: } 660 \text { unilat; } 155 \text { bilat } \mathrm{BC} \\
\text { C: } 448 \text { middle aged females; }\end{array}$ & $\begin{array}{l}\text { c.1100delC } \\
\text { (ASO PCR) }\end{array}$ & $\begin{array}{c}9.8(1.34-198.26) ; 0.007 \\
\text { - early onset/bilat BC/C carriers frequencies: } \\
3.4 / 5.2 / 0.2 \%\end{array}$ \\
\hline $\begin{array}{l}\text { Cybulski } 2004 \\
{[20]}\end{array}$ & PL & $\begin{array}{l}\text { P: } 1017 \text { BC } \\
\text { C: } 4000 \text { PMC }\end{array}$ & $\begin{array}{l}\text { c.1100delC; c. } 444+1 G>A ; \\
\text { p.I157T }\end{array}$ & $\begin{array}{c}2.2 ; p=0.02 \text {-for c.1100delC and c. } 444+1 \mathrm{G}>\mathrm{A} \\
1.4 ; p=0.02 \text {-for } p .1157 \mathrm{~T}\end{array}$ \\
\hline $\begin{array}{l}\text { Caligo 2004 } \\
\quad[130]\end{array}$ & IT & $\begin{array}{c}\left.\text { P: } 939 \text { BC (incl. } B R C A 1 / 2^{+v e}\right) \\
\text { C: } 334 \text { PMC }\end{array}$ & c.1100delC & $\begin{array}{l}\text { N.S.; frequency of carriers } 0.11 \%(95 \% \text { CI } \\
0.00-0.59 \%)\end{array}$ \\
\hline $\begin{array}{l}\text { Dufault } 2004 \\
{[165]}\end{array}$ & $\mathrm{DE}$ & $\begin{array}{c}\text { P: } 516 \text { BRCA1/2-ve BC } \\
\text { C: } 500 \text { PMC (1,315 PMC for } \\
\text { c. } 1100 \mathrm{delC})\end{array}$ & CHEK2 & $\begin{array}{c}3.44(1.19-9.95) ; 0.016-c .1100 \mathrm{delC} \\
3.9(1.3-10.9)-c .1100 \mathrm{delC} \text { and c.1214del4 }\end{array}$ \\
\hline $\begin{array}{c}\text { CHEK2 BC consortium } \\
2004 \\
{[166]}\end{array}$ & $\begin{array}{l}\mathrm{UK} / \mathrm{NL} / \mathrm{FI} / \\
\mathrm{DE} / \mathrm{AU}\end{array}$ & $\begin{array}{c}\text { P: } 10,860 \text { BC } \\
\text { C: } 9065 \text { multinatl. }\end{array}$ & c.1100delC & $\begin{array}{c}2.34(1.72-3.20) ; 1 \times 10^{-7} \text {-all } \mathrm{BC} \\
2.23(1.60-3.11)-\mathrm{BC} \text { w/o } \mathrm{BC} \text { in } 1^{\circ} \text { relative } \\
3.12(1.90-5.15)-\mathrm{BC} \text { with } 1 \mathrm{BC} \text { in } 1^{\circ} \text { relative } \\
4.17(1.26-13.75)-\mathrm{BC} \text { with } \geq 2 \mathrm{BC} \text { in } 1^{\circ} \text { relatives }\end{array}$ \\
\hline $\begin{array}{c}\text { CHEK2 BC consortium } \\
2002 \\
{[167]}\end{array}$ & $\begin{array}{l}\mathrm{UK} / \mathrm{NL} / \\
\mathrm{US} / \mathrm{CA}\end{array}$ & $\begin{array}{l}\text { P: } 636 \text { unselected BC } \\
\text { P: } 718 B R C A 1 / 2^{-v e} \text { BC } \\
\text { C: } 1620 \text { multinatl. }\end{array}$ & c.1100delC & $\begin{array}{c}2.52(0.78-8.18) \text { —unselected BC } \\
1.70(1.32-3.38) \text {-BRCA1/2-ve BC }\end{array}$ \\
\hline $\begin{array}{l}\text { Vahteristo } 2002 \\
\quad[110]\end{array}$ & FI & $\begin{array}{c}\text { P: } 1035 \text { unselected BC } \\
\text { C: } 1885 \text { PMC (blood donors) }\end{array}$ & c.1100delC & $\begin{array}{c}1.48 \text { (0.83-2.65); } 0.182 \text { - unselected BC } \\
2.27(1.11-4.63) ; 0.021 \text {-familial BC } \\
6.17 \text { (1.87-20.32); } 0.007 \text { bilat. vs. unilat. BC }\end{array}$ \\
\hline
\end{tabular}


Table 1. Cont.

\begin{tabular}{|c|c|c|c|c|}
\hline Reference & Population & $\begin{array}{l}\text { P: Patients } \\
\text { C: Controls }\end{array}$ & Analysis * & $\begin{array}{c}\text { Odds Ratio (95\% Confidence Interval); } \\
\text { p-Remark } \\
\text { (Statistically Insignificant in Italics) }\end{array}$ \\
\hline \multicolumn{5}{|c|}{ Male breast cancer } \\
\hline $\begin{array}{c}\text { Kleiblova } 2019 \\
\text { [115] }\end{array}$ & $\mathrm{CZ}$ & $\begin{array}{l}\text { P: } 48 \text { male BC } \\
\text { C: } 3360 \text { PMC }\end{array}$ & CHEK2 (panel NGS) & $\begin{array}{c}20.21(3.50-80.00) ; 8.6 \times 10^{-4} \text {-truncations } \\
11.87(0.25-100.83) ; 0.1 \text {-deleterious missense }\end{array}$ \\
\hline $\begin{array}{l}\text { Liang } 2018 \\
{[168]}\end{array}$ & meta & $\begin{array}{c}\text { P: } 1063 \text { male BC } \\
\text { C: } 31,571\end{array}$ & c.1100delC & $3.13(1.94-5.07)$ \\
\hline $\begin{array}{c}\text { Hallamies } 2017 \\
\text { [169] }\end{array}$ & FI & $\begin{array}{c}\text { P: } 68 \text { male BC } \\
\text { C: } 1885 \text { from [110] }\end{array}$ & c.1100delC & 4.47 (1.51-13.18); 0.019 \\
\hline $\begin{array}{c}\text { Wasielewski } 2009 \\
{[170]}\end{array}$ & NL & $\begin{array}{l}\text { P: } 71 \text { male BC } \\
\text { C: } 1692\end{array}$ & c.1100delC & $4.1(1.2-14.3) ; 0.05$ \\
\hline $\begin{array}{c}\text { CHEK2 consortium } 2002 \\
\text { [167] }\end{array}$ & $\mathrm{UK} / \mathrm{NL} / \mathrm{US} / \mathrm{CA}$ & $\begin{array}{l}\text { P: } 52 \text { male BC families } \\
\text { C: } 1620 \text { multinatl. }\end{array}$ & c.1100delC & $10.28(3.54-29.87)$ \\
\hline \multicolumn{5}{|c|}{ Meta-analyses } \\
\hline $\begin{array}{l}\text { Yang } 2019 \\
\text { [171] }\end{array}$ & $\begin{array}{c}\mathrm{BCAC}+\mathrm{ABCC} \\
\text { meta }\end{array}$ & $\begin{array}{c}\text { P: } 122,977+24,206 \text { BC } \\
\text { C: } 105,974+24,775 \text { PMC }\end{array}$ & p.I157T & $\begin{array}{c}1.28(1.17-1.39) ; 9.66 \times 10^{-9} \text {-for Europeans } \\
\text { only } \\
1.35(1.18-1.54) ; 9.82 \times 10^{-6} \text {-for } E^{+v e} B C \\
0.95(0.81-1.12) ; 0.55 \text {-for } E R^{-v e} B C\end{array}$ \\
\hline $\begin{array}{l}\text { Liang } 2018 \\
\quad[168]\end{array}$ & meta & $\begin{array}{l}\text { P: } 118,735 \text { BC } \\
\text { C: } 195,807\end{array}$ & c.1100delC & $\begin{array}{c}2.88(2.65-3.22) \text {-female BC } \\
\text { 2.87 (1.85-4.47)—early-onset BC } \\
3.21(2.41-4.29) \text {-familial BC } \\
3.13(1.94-5.07) \text {-male BC }\end{array}$ \\
\hline $\begin{array}{c}\text { Aloraifi } 2015 \\
\text { [113] }\end{array}$ & meta & $\begin{array}{l}\text { P. } 7283 \\
\text { C: } 13,785\end{array}$ & CHEK2 truncations & $3.25(2.55-4.13)$ \\
\hline $\begin{array}{c}\text { Han } 2013 \\
{[172]}\end{array}$ & meta & $\begin{array}{c}\text { P: } 15,985 \mathrm{BC} \\
\text { C: } 18,609\end{array}$ & p.I157T & $1.58(1.42-1.75) ;<0.0001$ \\
\hline $\begin{array}{c}\text { Liu } 2012 \\
{[173]}\end{array}$ & meta & $\begin{array}{c}\text { P: } 19,621 \mathrm{BC} \\
\text { C: } 27,001\end{array}$ & p.I157T & $\begin{array}{c}1.48(1.31-1.68) ;<0.0001 \text { - unselected BC } \\
1.48(1.16-1.89) ;<0.0001 \text {-familiar BC } \\
1.47(1.29-1.66) ;<0.0001 \text { - early onset BC } \\
4.17(2.89-6.03) ;<0.0001 \text {-lobular BC }\end{array}$ \\
\hline
\end{tabular}


Table 1. Cont.

\begin{tabular}{|c|c|c|c|c|}
\hline Reference & Population & $\begin{array}{l}\text { P: Patients } \\
\text { C: Controls }\end{array}$ & Analysis * & $\begin{array}{c}\text { Odds Ratio (95\% Confidence Interval); } \\
\text { p-Remark } \\
\text { (Statistically Insignificant in Italics) }\end{array}$ \\
\hline $\begin{array}{c}\text { Yang } 2012 \\
\text { [174] }\end{array}$ & meta & $\begin{array}{c}P: 29,154 \mathrm{BC} \\
\text { C: } 37,064\end{array}$ & c.1100delC & $\begin{array}{c}2.33(1.79-3.05) \text { - unselected BC } \\
3.72(2.61-5.31) \text {-familiar BC } \\
2.78(2.28-3.39) \text { - early onset BC }\end{array}$ \\
\hline $\begin{array}{c}\text { Zhang } 2011 \\
\text { [175] }\end{array}$ & meta & $\begin{array}{l}\text { P: } 9970 / C: 7526 \\
\text { P: } 13,331 / C: 10,817 \\
\text { P: } 10,543 / C: 10,817 \\
\text { P: } 41,791 / C: 50,910\end{array}$ & $\begin{array}{l}\text { c. } 444+1 \mathrm{G}>\mathrm{A} \\
\text { del5395 } \\
\text { c. } 1100 \mathrm{delC} \\
\text { p.I157T }\end{array}$ & $\begin{array}{c}3.07(2.03-4.63) ; 9.82 \times 10^{-8} \text {-for variant } \\
\text { c.444+1G>A } \\
2.53(1.61-3.97) ; 6.33 \times 10^{-5} \text { _for variant } \\
\text { del5395 } \\
3.10(2.59-3.71) ;<10^{-20} \text {-for variant c. } 1100 \mathrm{delC} \\
1.52(1.31-1.77) ; 4.76 \times 10^{-8} \text {-for variant } \mathrm{p} . \mathrm{I} 157 \mathrm{~T}\end{array}$ \\
\hline $\begin{array}{l}\text { Weischer } 2008 \\
\text { [176] }\end{array}$ & meta & $\begin{array}{l}\text { P: } 26,488 \\
C: 27,402\end{array}$ & c.1100delC & $\begin{array}{c}2.7(2.1-3.4) \text { - unselected BC } \\
2.6(1.3-5.5) \text { - early onset BC } \\
4.8(3.3-7.2) \text {-familial BC }\end{array}$ \\
\hline
\end{tabular}

${ }^{*}$ CHEK2 $=$ an analysis of the entire coding sequence (dominantly without copy number variations (CNV)); otherwise specified if certain CHEK2 variants were genotyped. AU-Australia; ABCC—Asian Breast Cancer Consortium; BC—breast cancer; BCAC—Breast Cancer Association Consortium; CA-Canada; CN-China; CZ-Czech Republic; DE-Germany; DK—Denmark; ES—Spain; EU—European Union; ExAC—Exome Aggregation Consortium; FI—Finland; FLOSSIES—Fabulous Ladies Over Seventy; FR—France; meta—meta-analysis; GR-Greece; IT-Italy; LoF-loss-of-function; JP—Japan; NL—Netherlands; PL—Poland; PMC—population-matched control; RU—Russia; US-the USA. The analyses that failed to demonstrate an association are shown in italics. 


\subsection{Breast Cancer}

Most studies of $C H E K 2$ germline mutations have dealt with breast cancer patients. The estimated OR for carriers of CHEK2 mutations varies among the studies considerably depending on analyzed populations, CHEK2 variants, and used controls (Table 1 ).

The variability of risk estimates is influenced by several important parameters, including the number and (pre)selection criteria of eligible patients, CHEK2 variants analyzed and considered pathogenic, and control group selection. The estimated lifetime risk of breast cancer for CHEK2 mutation carriers (mostly c.1100delC) differs according to family cancer history and ranges from 20 to $40 \%$ in women without and with a positive family breast cancer history, respectively [150]. More specifically, Cybulski and colleagues [159] estimated the lifetime BC risk for truncating CHEK2 mutations in Polish patients to be $20 \%$ in women without a family cancer history and $28 \%$ and $34 \%$ in women with a second- and first-degree relatives with BC, respectively. A Danish case-control study determined an absolute 10 -year BC risk as $24 \%$ in women carrying c.1100delC and older than 60 years undergoing hormone replacement therapy (HRT) with BMI > 25 [162]. Johnson et al. [177] estimated a cumulative risk of $58.8 \%$ (95\% CI 33.8-85.3) for breast cancer by the age of 80 for first-degree relatives of c.1100delC carriers with bilateral breast cancer from the UK. An international European study predicted the lifetime risk for BC in daughters of c.1100delC carriers and noncarriers with bilateral breast cancer as $37 \%$ and $18 \%$, respectively [161]. It can be assumed that breast cancer risk associated with pathogenic CHEK2 variants in the general population would be at the lower moderate penetrance gene border ( $\mathrm{OR}>2$ ) but considerably higher (though still in a moderate penetrance range; with $\mathrm{OR}<4$ ) for high-risk carriers from families with a positive cancer history. A precise evaluation of the associated risk will require large studies of unselected cancer patients with an appropriately selected population of geographically matched controls. A more precise estimate of individual breast cancer risks associated with germline CHEK2 mutations could be reached by considering the polygenic risk score (PRS) [178-180].

Breast cancer in the carriers of pathogenic germline CHEK2 mutations has several recurrently reported clinicopathological characteristics. The most striking is the development of bilateral breast cancer, as shown in some studies (Table 1). A recent meta-analysis by Akdeniz and colleagues [181] computed the relative risk of contralateral breast cancer development as 2.68 (95\% CI 1.69-3.65) for c.1100delC mutation carriers versus noncarriers (which was fully comparable with that in BRCA2 mutation carriers: $\mathrm{RR}=2.75 ; 95 \% \mathrm{CI} 1.77-4.29$ ). A significantly younger cancer onset in CHEK2 mutation carriers has been reported less consistently [152,154,182]. Published studies have also pointed out a worse breast cancer prognosis for c.1100delC mutation carriers [183-186] but not for p.I157T carriers [187]. Since the first studies, CHEK2 germline mutations have frequently been associated (in $85-90 \%$ of cases) with estrogen receptor positive (ER+) breast cancer subtypes $[115,126,139,183,188$, 189]. Consistent with that, no CHEK2 mutation carriers were observed in an analysis of 1824 triple negative breast cancer patients [190]. A large analysis conducted by the BCAC consortium estimated the cumulative risk of developing ER+ and ER- breast cancer by the age of 80 for c.1100delC mutation carriers at $20 \%$ and $3 \%$, respectively, compared with $9 \%$ and $2 \%$, respectively, in the general British population [155].

Although ER+ tumors tend to have a better prognosis in unselected breast cancer patients, ER+ tumors in CHEK2 mutation carriers were associated with worse breast cancer-specific survival [155,184]. A low or significantly reduced CHK2 expression was found in most breast tumors from mutation carriers [191]. Interestingly, both tumors with low CHK2 expression and tumors from CHEK2 mutation carriers were associated with increased grade, especially with a lower proportion of grade one tumors [115,192]. Bahassi and colleagues [193] offered an interesting hypothesis describing a link between ER positivity and reduced CHK2 expression based on the observation of mouse models. They noticed that the ER stimulated c-MYC transcriptional activity, increasing CDC25A expression that in turn resulted in the S-phase entry and genomic instability in mice homozygous or heterozygous for Chk2 c.1100delC. An association with lobular breast cancer was reported for p.I157T in patients 
from Poland [194] and the Czech Republic [115] and from a meta-analysis by Liu and colleagues [173] for pathogenic CHEK2 mutations in patients from Slovenia [182] and for other germline variants in patients from Bulgaria [195].

All in all, germline CHEK2 mutations confer increased risk of the development of ER-positive breast cancer with an unfavorable prognosis and an increased risk of bilateral breast cancer. The current NCCN guidelines (National Comprehensive Cancer Network guidelines version 1.2021 for Genetic/Familial High-Risk Assessment: Breast, Ovarian, and Pancreatic) recommend annual mammogram screenings for women carrying a pathogenic mutation since the age of 40 and recommend an annual MRI check. The risk-reducing mastectomy (RRM) is not generally recommended because of the lack of data confirming its benefits; however, RRM can be considered, especially based on family cancer history [196]. Prophylactic contralateral mastectomy can also be recommended for breast cancer patients with pathogenic CHEK2 germline mutations. Chemoprevention for unaffected women with pathogenic mutations could be considered as an option [197].

An increased risk of male breast cancer has been documented in few smaller studies (Table 1); however, due to the low overall male breast cancer risk, its increase would not substantiate a specific follow-up, although the association should be considered in case of breast pathology developing in male mutation carriers. The RRM is not recommended in male CHEK2 mutation carriers [196].

The relatively high frequency of germline CHEK2 mutations in some populations and the dispensability of CHK2 for normal development results in identification of recessive homozygotes or compound heterozygotes carrying CHEK2 mutations at both alleles. Sutcliffe and colleagues reported $32(1.3 \%)$ homozygotes among 2508 identified CHEK2 mutation carriers [114]. The most frequent ones were c.1100delC and p.I157T homozygotes, of whom $66 \%$ and $60 \%$ were diagnosed with BC, respectively. Rainville summarized data from 31 biallelic mutation carriers identified among 6473 monoallelic CHEK2 mutation carriers tested by Myriad Genetics, of whom 16/31 were c.1100delC mutation carriers [104]. Compared with monoallelic carriers, biallelic carriers developed breast cancer more frequently ( $81 \%$ vs. $41 \%$; $p<0.0001)$ and more likely before the age of $50(61 \%$ vs. $24 \%$; $p<0.0001)$, they developed secondary breast cancer with a higher frequency $(23 \% \mathrm{vs.} 8 \% ; p=0.01)$, and finally they had a higher risk of developing any primary cancer and multiple primary cancer. The ORs for the development of ductal carcinoma in situ (DCIS) and ductal carcinoma were high (OR 8.7, 95\% CI 3.7-20.5 and OR 5.0, 95\% CI 2.0-12.4, respectively) [104]. Case reports of homozygous carriers, which included other CHEK2 mutations, have been published episodically [103,198,199], and they indicate an increased risk of the development of variable primary cancers with an early age at onset. These data support an intensified management of homozygous carriers of CHEK2 pathogenic mutations. In the case of breast cancer, the surveillance follow-up should copy that in BRCA1/BRCA2 mutation carriers. The prevention of other tumors associated with germline CHEK2 mutations should be considered. While p.I157T is considered a low penetrance variant, we assume that, based on functional data, homozygotes should be managed in a way similar to c.1100delC heterozygotes [115].

\subsection{Prostate Cancer}

The association of CHEK2 with prostate cancer was already proposed in 2003, when Dong and colleagues identified 18 unique CHEK2 mutations in 15/400 (3.75\%) patients with sporadic prostate cancer and in 11/298 (3.69\%) patients with familial prostate cancer [200]. This association has been confirmed by subsequent studies (Table 2), and a CHEK2 gene analysis is currently routinely performed as part of prostate-specific gene panels [201]. 
Table 2. Analyses of the entire CHEK2 coding sequence (separately or as part of panel NGS) or analyses of specific variant(s) in prostate cancer (PrC) patients.

\begin{tabular}{|c|c|c|c|c|}
\hline Reference & Population & $\begin{array}{l}\text { P: Patients } \\
\text { C: Controls }\end{array}$ & Analysis ** & $\begin{array}{c}\text { Odds Ratio (95\% Confidence Interval); } \\
\text { p-Remark } \\
\text { (Statistically Insignificant in Italics) }\end{array}$ \\
\hline $\begin{array}{l}\text { Brandao } 2020 \\
\quad[202]\end{array}$ & $\begin{array}{c}\text { PT } \\
\text { PRACTICAL }\end{array}$ & $\begin{array}{c}\text { P: } 462 \text { early-onset/familial PrC } \\
\text { C: } 710 \text { PMC } \\
\text { P: 55,162 PrC/C: } 36,147\end{array}$ & c.349A>G (p.R117G) & $\begin{array}{c}7.7 \text { (0.9-66.6); 0.06—PT PrC p.R117G } \\
1.9(1.1-3.2) ; 0.04 \text {-PRACTICAL PrC p.R117G }\end{array}$ \\
\hline $\begin{array}{c}\text { Momozawa } 2018 \\
\text { [144] }\end{array}$ & $\mathrm{JP}$ & $\begin{array}{l}\text { P: } 7636 \\
\text { C: } 12,366\end{array}$ & Panel NGS (8 genes) & $2.43(0.91-6.86) ; 0.06$ \\
\hline $\begin{array}{l}\text { Conti } 2017 \\
\text { [203] }\end{array}$ & $\mathrm{AAPC}, \mathrm{GH}$ & $\begin{array}{l}\text { AAPC-P:4,853 PrC; C: } 4678 \\
\text { GH-P: 474; C: } 458\end{array}$ & $\begin{array}{c}\text { GWAS array (rs78554043 = } \\
\text { rs17886163; CHEK2 c. } 1343 \mathrm{~T}>\mathrm{G} ; \\
\text { p.I448S) }\end{array}$ & $\begin{array}{l}1.60(1.27-2.00) ; 5.02 \times 10^{-5} \text { _for AAPC PrC } \\
2.45 \text { (1.33-4.52); } 0.004 \text {-for Ghana PrC }\end{array}$ \\
\hline Naslund-Koch 2016 [156] & DK & $\begin{array}{l}86,975 \text { individuals (longitudinal } \\
\text { study); } 1340 \text { developed } \operatorname{PrC}\end{array}$ & c.1100delC & $1.60(1.00-2.56) ; 0.05$ \\
\hline $\begin{array}{l}\text { Southey } 2016 \\
\text { [157] }\end{array}$ & OCAC & $\begin{array}{l}\text { P: } 22,301 \text { PrC } \\
\text { C: } 22,320 \text { PMC }\end{array}$ & $\begin{array}{c}\text { iCOGS array } \\
\text { incl. } 6 \text { rare CHEK2 variants }\end{array}$ & $\begin{array}{c}1.46(0.71-3.02) ; 0.3 \text { - for } p . R 117 G \\
1.02(0.73-1.44) ; 0.9 \text { - for } p . R 180 \mathrm{C} \\
1.47(0.41-5.35) ; 0.6 \text { - for } p . E 239 \mathrm{~K} \\
1.07(0.28-4.07) ; 0.9 \text {-for } p . D 438 Y \\
2.21(1.06-4.63) ; 0.03 \text {-for } p . D 438 \mathrm{Y} \\
3.03(1.53-6.03) ; 0.001 \text { - for I448S in Africans }\end{array}$ \\
\hline $\begin{array}{c}\text { Pritchard } 2016 \\
\text { [118] }\end{array}$ & US, UK & $\begin{array}{l}\text { P: } 692 \text { metastat. PrC } \\
\text { C: ExAC/TCGA }\end{array}$ & Panel NGS & $\begin{array}{l}3.1(1.5-5.6) ; 0.002 \text {-vs. ExAC (excl. p.I157T) } \\
4.7(2.2-8.5) ;<0.001 \text {-vs. TCGA (excl. p.I157T) }\end{array}$ \\
\hline $\begin{array}{l}\text { Wang } 2015 \\
\quad[204]\end{array}$ & meta & $\begin{array}{l}\text { P: } 6409 \operatorname{PrC} \\
\text { C: } 11,634\end{array}$ & $\begin{array}{l}\text { c. } 1100 \text { delC } \\
\text { c. } 444+1 G>A \\
\text { p.I157T }\end{array}$ & $\begin{array}{c}3.29(1.85-5.85) ;<0.001-c .1100 \text { delC } \\
1.59(0.79-3.20) ; 0.20-c .1100 d e l C, \text { familial } \\
1.58(0.93-2.71) ; 0.09-c .444+1 G>A \\
1.80(1.51-2.14) ;<0.001-\text { p.I157T }\end{array}$ \\
\hline $\begin{array}{l}\text { Hale 2014 } \\
\text { [205] }\end{array}$ & meta & $\begin{array}{l}P: 5,124 \operatorname{PrC} \\
\text { C: } 9,258\end{array}$ & c.1100delC & $\begin{array}{c}1.98 \text { (1.23-3.18); } 0.004 \text { - unselected } \\
3.39 \text { (1.78-6.47); } 0.0001 \text {-familial }\end{array}$ \\
\hline $\begin{array}{l}\text { Cybulski } 2006 \\
\text { [206] }\end{array}$ & PL & $\begin{array}{l}\text { P: } 1864 \text { PrC (incl. } 249 \text { famil.) } \\
\text { C: } 5496\end{array}$ & $\begin{array}{l}\text { c.1100delC; c. } 444+1 \mathrm{G}>\mathrm{A} ; \\
\text { 5395del; } \\
\text { p.I157T }\end{array}$ & $\begin{array}{c}2.3(1.1-3.9) ;<0.001-\text { truncations, sporadic } \\
4.7(2.5-9.0) ;<0.001-\text { truncations, familial } \\
1.6(1.3-2.0) ;<0.001-\text { p.I157T, sporadic } \\
2.7(1.8-4.1) ;<0.001-\text { p.I157T, familial }\end{array}$ \\
\hline
\end{tabular}


Table 2. Cont.

\begin{tabular}{|c|c|c|c|c|}
\hline Reference & Population & $\begin{array}{l}\text { P: Patients } \\
\text { C: Controls }\end{array}$ & Analysis ** & $\begin{array}{l}\text { Odds Ratio (95\% Confidence Interval); } \\
\text { p-Remark } \\
\text { (Statistically Insignificant in Italics) }\end{array}$ \\
\hline $\begin{array}{c}\text { Weischer } 2007 \\
{[162]}\end{array}$ & DK & $\begin{array}{c}\text { P: } 116 \text { PrC (prospective) } \\
\text { C: } 3999 \text { PMC men (prospect.) }\end{array}$ & c.1100delC & 2.3 (0.6-9.5) PrC prospective study \\
\hline $\begin{array}{c}\text { Johnson } 2005 \\
\text { [177] }\end{array}$ & UK & P: 469 bilat. BC & c.1100delC & $\begin{array}{l}2.41(1.67-3.36) \text { - risk of } \operatorname{PrC} \text { for relatives of } \\
\text { patients with bilateral BC }\end{array}$ \\
\hline $\begin{array}{c}\text { Cybulski } 2004 \\
{[20]}\end{array}$ & PL & $\begin{array}{c}\text { P: } 690 \text { PrC } \\
\text { C: } 4000 \text { PMC }\end{array}$ & $\begin{array}{l}\text { c.1100delC; c.444+1G>A; } \\
\text { p.I157T }\end{array}$ & $\begin{array}{l}\text { 2.2; } 0.04-\text { truncations } \\
1.7 ; 0.002-\text { p.I157T }\end{array}$ \\
\hline $\begin{array}{l}\text { Seppala } 2003 \\
\text { [207] }\end{array}$ & FI & $\begin{array}{l}\text { P1: } 537 \text { unselected } \operatorname{PrC} ; \\
\text { P2: } 120 \text { hereditary PrC } \\
\text { C: } 510 \text { non-PrC men }\end{array}$ & $\begin{array}{l}\text { CHEK2 (SSCP: heredit. PrC) } \\
\text { c.1100delC/p.I157T }\end{array}$ & $\begin{array}{c}3.14 \text { (0.65-15.16); 0.15-c.1100delC, sporadic } \\
8.24(1.49-45.54) ; 0.02-c .1100 \mathrm{delC} \text {, hereditary } \\
1.48(0.89-2.46) ; 0.13-\text { p.I157T, sporadic } \\
2.12(1.06-4.27) ; 0.04-\text { p.I157T, hereditary }\end{array}$ \\
\hline $\begin{array}{l}\text { Dong } 2003 \\
\text { [200] }\end{array}$ & US & $\begin{array}{l}\text { P1: } 400 \text { sporadic PrC; } \\
\text { P2: } 298 \text { familial PrCC: } 510 \\
\text { non-PrC men }\end{array}$ & CHEK2 (DHPLC) & $\begin{array}{c}2.71(1.04-7.04) ; 0.049^{*} \text { - sporadic } \operatorname{PrC} \\
2.66(0.98-7.28) ; 0.078^{*} \text {-familial } \operatorname{PrC} \\
6.84(0.86-54.1) ; 0.05^{*} \text {-sporadic }(w / o \text { p.I157T) } \\
5.74(0.64-51.5) ; 0.17^{*} \text { _familial }(w / o \text { p.I157T) }\end{array}$ \\
\hline
\end{tabular}


A study by Pritchard et al. demonstrated that 82/692 (11.8\%) men with metastatic prostate cancer carry a mutation in some of the 16 analyzed DNA repair genes. The carriers of $B R C A 2(\mathrm{~N}=37 ; 44 \%)$, $\operatorname{ATM}(\mathrm{N}=11 ; 13 \%), \operatorname{CHEK2}(\mathrm{N}=10 ; 12 \%)$, and BRCA1 $(\mathrm{N}=6 ; 7 \%)$ represented over $75 \%$ of all mutation carriers. These data confirmed a report by Isaacsson Velho and colleagues [209], who found a similar proportion of mutation carriers $(21 / 150 ; 14 \%)$ among unselected prostate cancer patients with an identical proportion of affected genes: BRCA2 $(\mathrm{N}=9 ; 43 \%), A T M(\mathrm{~N}=3 ; 14 \%)$, CHEK2 $(\mathrm{N}=3 ; 14 \%)$, and $B R C A 1(\mathrm{~N}=2 ; 9 \%)$. Moreover, patients with germline mutations had significantly more frequent intraductal histology $(47.6 \%$ vs. $11.6 \%$ in noncarriers; $p=0.003)$ and presence of lymphovascular invasion $(52.3 \%$ vs. $13.9 \%$; $p<0.001)$. Thus, the authors concluded that genetic testing should be offered to patients with these clinicopathological characteristics. A larger cross-sectional analysis of 1328 men with prostate cancer by Giri and colleagues [210] found $15.6 \%$ carriers of germline mutations; $10.9 \%$ patients carried a mutation in DNA repair genes (BRCA2 >CHEK2 $>A T M>B R C A 1)$, increasing the risk of more advanced tumors (Gleason score $\geq 8$ ). CHEK2 mutations were less frequent in prostate cancer patients from Japan [144].

$\mathrm{Wu}$ and colleagues analyzed survival characteristics in prostate cancer patients carrying germline CHEK2 mutations [211]. Although they found no association between the CHEK2 mutation status and early diagnosis or PrC, they noted that c.1100delC mutation carriers are more prevalent among patients with a lethal disease than in patients with low-risk prostate cancer $(1.28 \%$ vs. $0.16 \% ; p=0.004)$. Yadav et al. [212] found no significant association between the presence of germline mutations and survival characteristics, but they found that mutations in ATM, BRCA2, CHEK2, FANCM, and TP53 were significantly more frequent in patients with a metastatic disease.

The performed studies present rather compelling evidence that CHEK2 is a low-to-moderate prostate cancer predisposition gene. Therefore, male carriers of pathogenic CHEK2 mutations, especially from families with multiple prostate cancers, deserve intensified prostate cancer screening which should include an annual PSA test from the age of 40. A report by Cybulski et al. [213] identified an increased proportion of p.I157T carriers among individuals with elevated PSA or an abnormal digital rectal examination versus individuals with normal assessments $(10.2 \%$ vs. $4.3 \%$; OR $=2.5 ; p=0.0008)$; however, a prostate-specific follow-up needs to be justified in larger studies.

\subsection{Kidney Cancer}

The p.I157T variant (but not the truncating founder mutations) was recognized to increase kidney cancer risk in a pioneering clinical study by Cybulski and colleagues [20]. Other studies (Table 3) confirmed an association between CHEK2 germline mutations and renal cell carcinoma later on, with the exception of an analysis by Ge et al. exploiting GWAS datasets. 
Table 3. Analyses of the entire CHEK2 coding sequence (separately or as a part of panel NGS) or analyses of specific variant(s) in renal cell carcinoma (RCC) patients.

\begin{tabular}{|c|c|c|c|c|}
\hline Reference & Population & $\begin{array}{l}\text { P: Patients } \\
\text { C: Controls }\end{array}$ & Analysis * & $\begin{array}{c}\text { Odds Ratio (95\% Confidence Interval); } \\
\text { p-Remark } \\
\text { (Statistically Insignificant in Italics) }\end{array}$ \\
\hline $\begin{array}{c}\text { Zlowocka-Perlowska } 2019 \\
{[214]}\end{array}$ & PL & $\begin{array}{l}\text { P: } 835 \text { invasive } \mathrm{RCC} \\
\text { C: } 8304 \text { non-cancer }\end{array}$ & $\begin{array}{c}\text { c.1100delC; c. } 444+1 \mathrm{~A}>\mathrm{G} ; \\
\text { 5395del; c.I157T }\end{array}$ & $\begin{array}{l}2.5(1.5-4.1) ; 0.0003 \text {-for truncations } \\
2.0(1.6-2.6) ;<0.001 \text {-for p.I157T }\end{array}$ \\
\hline $\begin{array}{l}\text { Carlo } 2018 \\
\text { [215] }\end{array}$ & US & $\begin{array}{c}\text { P: } 254 \text { RCC (stage III-IV) } \\
\text { C: ExAC }\end{array}$ & CHEK2 & $3.0(1.3-5.8) ; 0.003$ \\
\hline $\begin{array}{c}\text { Ge } 2016 \\
\text { [216] }\end{array}$ & GWAS & $\begin{array}{l}\text { P: } 1322 \\
\text { C: } 3428\end{array}$ & p.I157T & $0.63(0.44-0.89) ; 0.01$ \\
\hline $\begin{array}{l}\text { Naslund-Koch } 2016 \\
\text { [156] }\end{array}$ & DK & $\begin{array}{l}\text { 138/86,975 individuals } \\
\text { developed RCC }\end{array}$ & c.1100delC & $3.61(1.33-9.79) ; 0.01$ \\
\hline $\begin{array}{c}\text { Weischer } 2007 \\
\text { [162] }\end{array}$ & DK & $\begin{array}{l}\text { P: } 33 \text { RCC (prospective) } \\
\text { C: } 9166 \text { PMC (prospect.) }\end{array}$ & c.1100delC & 9.8 (2.3-41.2) RCC prospective study \\
\hline $\begin{array}{c}\text { Cybulski } 2004 \\
{[20]}\end{array}$ & PL & $\begin{array}{l}\text { P: } 264 \text { RCC } \\
\text { C: } 4000 \text { PMC }\end{array}$ & $\begin{array}{c}\text { c.1100delC; c.444+1G>A; } \\
\text { p.I157T }\end{array}$ & $\begin{array}{c}1.0 ; p=0.8 \text {-truncations } \\
2.1 ; p=0.0006 \text {-for } p . I 157 \mathrm{~T}\end{array}$ \\
\hline
\end{tabular}

${ }^{*}$ CHEK2 = an analysis of the entire coding sequence (dominantly without CNV); otherwise specified if certain CHEK2 variants were genotyped. DK-Denmark; GWAS- genome-wide association study; PL—Poland; US-the USA. The analyses that failed to demonstrate an association are shown in italics. 
NGS panel sequencing by Carlo and colleagues in 254 patients with advanced RCC identified 41 carriers of pathogenic germline mutations in renal cancer- or other cancer-associated genes [215]. Among them, germline mutations in CHEK2 found in nine (3.4\%) patients outnumbered the most frequent alterations in RCC-associated mutations (7× FH [2.8\%]; 3× BAP1 [1.2\%]). Consistently, $7 / 229(3.1 \%)$ mutation carriers with germline CHEK2 variants were identified among metastatic clear cell renal cancer patients by Ged and colleagues [217]. CHEK2 germline mutations were also the most frequent alterations found in 19/844 (2.25\%) patients with early onset RCC developed before the age of 60 [218]. Notably, among these, second primary cancers (breast, thyroid, colon, blood, and ovarian) were reported in 13 (68\%) individuals. With 3/118 (2.5\%) individuals suggestive of inherited RCC, CHEK2 was the second most frequently altered gene (following BRIP1) that is not routinely tested for renal cancer predisposition [219]. Unexpectedly, Gadd and colleagues identified germline CHEK2 variants in 3/117 (2.6\%) and 8/651 (1.2\%) patients with Wilms tumors in their discovery and validation sets, respectively [220]. Another report by Ciceri et al. [221] found five carriers of rare missense or splicing CHEK2 variants among 96 Wilms tumor patients from Italy. While evidence of the association of CHEK2 germline mutations with an increased RCC risk is currently mounting, larger case control studies in RCC patients are required to confirm and refine the magnitude of the associated risk.

\subsection{Papillary Thyroid Cancer}

A multiple cancer study by Cybulski et al. [20] identified an increased risk of thyroid cancer, particularly in carriers of CHEK2 truncations $(\mathrm{OR}=4.9)$ and, to a lesser extent, in carriers of p.I157T $(\mathrm{OR}=1.9)$. Observations from this study were confirmed subsequently (Table 4); however, most of the data originate from Poland only and will require confirmation from other populations. 
Table 4. Analyses of the CHEK2 variants in Polish (PL) patients with papillary thyroid cancer (PTC).

\begin{tabular}{|c|c|c|c|c|}
\hline Reference & Population & $\begin{array}{l}\text { P: Patients } \\
\text { C: Controls }\end{array}$ & $\begin{array}{c}\text { Analysis of Specific CHEK2 } \\
\text { Variants }\end{array}$ & $\begin{array}{c}\text { Odds Ratio (95\% Confidence Interval); } \\
\text { p-Remark } \\
\text { (Statistically Insignificant in Italics) }\end{array}$ \\
\hline $\begin{array}{c}\text { Kaczmarek-Rys } 2015 \\
\text { [222] }\end{array}$ & PL & $\begin{array}{c}\text { P: } 602 \text { differentiated PTC } \\
\text { C: } 829 \text { PMC }\end{array}$ & p.I157T & $\begin{array}{c}1.81(1.20-2.72) ; 0.004-p . I 157 T \text { heterozygote } \\
12.81(0.6-248.46) ; 0.02-p . I 157 T \\
\text { homozygote }\end{array}$ \\
\hline $\begin{array}{l}\text { Siolek } 2015 \\
\quad[223]\end{array}$ & PL & $\begin{array}{c}\text { P: } 468 \text { unselected PTC } \\
\text { C: } 468 \text { matched non-cancer }\end{array}$ & $\begin{array}{l}\text { c.1100delC; c.444+1G>A; } \\
\text { 5395del; } \\
\text { p.I157T }\end{array}$ & $\begin{array}{l}5.7 \text { (1.7-19.3); 0.006-truncations } \\
2.8(1.7-4.6) ; 0.0001-\text { p.I157T }\end{array}$ \\
\hline $\begin{array}{l}\text { Wojcicka } 2014 \\
{[224]}\end{array}$ & PL & $\begin{array}{c}\text { P: } 1781 \text { PTC } \\
\text { C: } 2081 \text { healthy PMC }\end{array}$ & p.I157T & $2.21(1.69-2.88) ; 2.37 \times 10^{-10}$ _for p.I157T \\
\hline $\begin{array}{c}\text { Cybulski } 2004 \\
{[20]}\end{array}$ & PL & $\begin{array}{l}\text { P: } 173 \text { PTC } \\
\text { C: } 4000 \text { PMC }\end{array}$ & $\begin{array}{l}\text { c.1100delC; c.444+1G>A; } \\
\text { p.I157T }\end{array}$ & $\begin{array}{l}4.9 ; 0.006 \text {-truncations } \\
1.9 ; 0.04-\text { p.I157T }\end{array}$ \\
\hline
\end{tabular}


Recently, Pekova et al. [225] identified pathogenic/likely pathogenic germline CHEK2 variants in $7 / 83(8.4 \%)$ Czech pediatric/adolescent patients with papillary thyroid cancer, detecting five $(6.0 \%)$ p.I157T carriers among them. An interesting report by Zhao and colleagues [226] described a Chinese family with the germline CHEK2 mutation c.417A $>C$ (p.Y139*; described independently as a recurrent germline mutation in Chinese breast cancer patients [142]) segregating in all four first-degree relatives with papillary thyroid cancer. The authors subsequently analyzed 242 sporadic papillary thyroid cancers and identified two carriers of the p.R180C variant and three carriers of p.H371Y.

Beyond the hereditary cancer genetics, somatic CHEK2 alterations were characterized as mutations that may contribute to tumor progression in papillary thyroid carcinoma [227].

\subsection{Colorectal Cancer}

Early studies performed by the CHEK2 consortium (Meijers-Heijboer and colleagues) identified families of c.1100delC carriers with apparently frequent breast and colorectal cancer and denoted this familial cancer cooccurrence as the "hereditary breast and colorectal cancer syndrome (HBCC)" [228]. c.1100delC carriers have a strong association with the HBCC phenotype and a trend increasing colorectal cancer risk in HNPCC and HNPCC-like families (Table 5). However, a follow-up study by Nasem and colleagues [229] failed to confirm this finding as they identified only a single c.1100delC carrier in 113 HBCC individuals. Several studies and meta-analyses have focused on colorectal cancer later on and provided evidence of a low-to-moderate risk for c.1100delC and low risk for p.I157T carriers. 
Table 5. Analyses of the entire CHEK2 coding sequence (separately or as a part of panel NGS) or analyses of specific variant(s) in colorectal cancer (CRC) patients.

\begin{tabular}{|c|c|c|c|c|}
\hline Reference & Population & $\begin{array}{l}\text { P: Patients } \\
\text { C: Controls }\end{array}$ & Analysis & $\begin{array}{l}\text { Odds Ratio (95\% Confidence Interval); } \\
\text { p-Remark } \\
\text { (Statistically Insignificant in Italics) }\end{array}$ \\
\hline $\begin{array}{l}\text { Xiang } 2017 \\
\text { [230] }\end{array}$ & meta & $\begin{array}{l}\text { Revision of the analysis from } \\
\text { [231] }\end{array}$ & & $\begin{array}{l}1.8(1.2-2.7) \text { - unselected CRC } \\
2.4(0.9-6.6) \text {-familial CRC } \\
1.7(0.9-2.9) \text {-sporadic CRC }\end{array}$ \\
\hline Naslund-Koch 2016 [156] & DK & $\begin{array}{c}\text { 1131/86,975 individuals } \\
\text { developed CRC }\end{array}$ & c.1100delC & $0.86(0.43-1.72) ; 0.68$ \\
\hline $\begin{array}{l}\text { Ma 2014 } \\
\text { [232] }\end{array}$ & meta & $\begin{array}{l}\text { P: } 3874 \text { CRC/ C:11,630 } \\
\text { P: } 6042 \text { CRC/ C:17,051 }\end{array}$ & $\begin{array}{l}\text { c.1100delC } \\
\text { p.I157T }\end{array}$ & $\begin{array}{c}1.88(1.29-2.73) ; 0.001 \\
1.56(1.32-1.84) ; 1.22 \times 10^{-7}\end{array}$ \\
\hline $\begin{array}{c}\text { Han } 2013 \\
{[172]}\end{array}$ & meta & $\begin{array}{c}\text { P: } 3166 \text { CRC } \\
\text { C: } 9844\end{array}$ & p.I157T & 1.67 (1.24-2.26); 0.0008 \\
\hline $\begin{array}{c}\text { Liu } 2012 \\
\text { [233] }\end{array}$ & meta & $\begin{array}{l}\text { P: } 4029 \text { CRC } \\
\text { C: } 13,844\end{array}$ & p.I157T & $\begin{array}{c}1.61(1.40-1.87) ;<0.001 \text { - unselected CRC } \\
1.48(1.23-1.77) ;<0.001 \text {-sporadic CRC } \\
1.97(1.41-2.74) ;<0.001 \text {-familial CRC }\end{array}$ \\
\hline $\begin{array}{l}\text { Xiang } 2011 \\
\text { [231] }\end{array}$ & meta & $\begin{array}{l}\text { P: } 4,194 \text { CRC } \\
\quad \text { C: } 10,010\end{array}$ & c.1100delC & $\begin{array}{c}2.11(1.41-3.16) ; 0.0003 \text { - unselected CRC } \\
2.80(1.74-4.51) ;<0.0001 \text {-familial CRC } \\
1.45(0.49-4.30) ; 0.5 \text {-sporadic CRC }\end{array}$ \\
\hline $\begin{array}{l}\text { Suchy } 2010 \\
\text { [234] }\end{array}$ & PL & $\begin{array}{c}\text { P: } 463 \text { HNPCC-related } \\
\text { C: } 5496 \text { PMC }\end{array}$ & $\begin{array}{l}\text { c.1100delC; c.444+1G>A; } \\
\text { del5395; } \\
\text { p.I157T }\end{array}$ & $\begin{array}{l}1.0(0.4-2.6) ; 1.0 \text {-truncations } \\
1.7(1.2-2.4) ; 0.007-\text { p.I157T }\end{array}$ \\
\hline $\begin{array}{l}\text { Kleibl } 2009 \\
\quad[235]\end{array}$ & $\mathrm{CZ}$ & $\begin{array}{l}\text { P: } 631 \text { CRC } \\
\text { C: } 683 \text { PMC }\end{array}$ & $\begin{array}{l}\text { FHA-coding region } \\
\text { c.1100delC;5395del }\end{array}$ & $\begin{array}{c}2.3(1.3-4.0) ; 0.003 \text { - all variants in FHA domain } \\
2.0(1.1-3.6) ; 0.03-\text { p.I157T only } \\
2.3(0.4-12.8) ; 0.4-c .1100 \text { delC; zero } 5395 \mathrm{del} \\
\text { carriers }\end{array}$ \\
\hline $\begin{array}{l}\text { Weischer } 2007 \\
\text { [162] }\end{array}$ & DK & $\begin{array}{c}\text { P: } 210 \text { (prospective) } \\
\text { C: } 9007 \text { PMC (prospect.) }\end{array}$ & c.1100delC & $1.6(0.4-6.5)$ - prospective $C R C$ \\
\hline $\begin{array}{c}\text { Cybulski } 2007 \\
{[236]}\end{array}$ & PL & $\begin{array}{l}\text { P. } 1085 \text { unselected CRC } \\
\text { C: } 5496 \text { controls }\end{array}$ & $\begin{array}{l}\text { c.1100delC; c.444+1G>A; } \\
\text { del5395; } \\
\text { p.I157T }\end{array}$ & $\begin{array}{l}1.0(0.5-1.8) ; 0.9 \text {-truncations } \\
1.5(1.2-2.0) ; 0.002-\text { p.I157T }\end{array}$ \\
\hline
\end{tabular}


Table 5. Cont.

\begin{tabular}{|c|c|c|c|c|}
\hline Reference & Population & $\begin{array}{l}\text { P: Patients } \\
\text { C: Controls }\end{array}$ & Analysis & $\begin{array}{l}\text { Odds Ratio (95\% Confidence Interval); } \\
\text { p-Remark } \\
\text { (Statistically Insignificant in Italics) }\end{array}$ \\
\hline $\begin{array}{c}\text { Djureinovic } 2006 \\
\text { [237] }\end{array}$ & SE & $\begin{array}{c}\text { P: } 174 \text { familial CRC } \\
\text { P: } 644 \text { unselected CRC } \\
\text { C: } 760 \text { PMC }\end{array}$ & c.1100delC & $\begin{array}{l}1.76(0.34-9.09) ; 0.6 \text {-familial CRC } \\
1.42(0.43-4.67) ; 0.7 \text {-sporadic CRC }\end{array}$ \\
\hline $\begin{array}{l}\text { Irmejs } 2006 \\
\text { [133] }\end{array}$ & LV & $\begin{array}{c}\text { P: } 235 \\
\text { C: } 978 \text { newborn PMC }\end{array}$ & p.I157T & $1.7(1.01-2.70) ; p<0.05$ \\
\hline $\begin{array}{l}\text { Meijers-Heijboer } 2003 \\
\text { [228] }\end{array}$ & $\begin{array}{l}\mathrm{UK} / \mathrm{NL} / \\
\mathrm{US} / \mathrm{CA}\end{array}$ & $\begin{array}{l}\text { P: } 329 \text { CRC } \\
\text { C: } 1620[167]\end{array}$ & c.1100delC (ASO) & $\begin{array}{c}2.34 \text { (0.95-5.79); 0.07-HNPCC-like families } \\
5.19(2.17-12.4) ;<0.001-\text { HBCC families }\end{array}$ \\
\hline
\end{tabular}

association are shown in italics. 
Targeted NGS revealed that CHEK2 was the second most frequently altered gene (following heterozygous MUTYH) in the Ambry Genetics ColoNext panel with germline CHEK2 mutations found in 8/586 colon cancer patients [238]. Subsequent NGS of 450 early-onset colorectal cancer patients from Ohio utilizing a 25-gene panel identified only one CHEK2 pathogenic mutation; however, the authors reported another 18 CHEK2 variants as VUS (including six p.I157T) [239]. A recent study of 46 genes in 151 patients with advanced colorectal cancer found 15 carriers of germline mutations. Among them, CHEK2 with four mutation carriers was the most frequently altered gene [240].

The published data do not provide consistent evidence that germline CHEK2 alterations substantially contribute to increased colorectal cancer risk. Therefore, the magnitude of colorectal cancer risk needs to be precisely estimated before the formulation of recommendations for a tailored follow-up in mutation carriers. Until then, intensified surveillance may be considered for carriers of CHEK2 pathogenic mutations from families with multiple appearances of colorectal cancer [241].

\subsection{Other Cancers}

In 2004, Cybulski and colleagues hypothesized that the portfolio of cancers associating with CHEK2 germline mutations reaches beyond breast and prostate cancers and identified associations with few other cancer types [20]. However, dozens of isolated studies have reported an association of germline CHEK2 mutations with an increased, decreased, or no risk in particular types of solid cancers. An increased risk has been documented in patients with melanoma [242], endometrial $[243,244]$, or testicular cancer [245]. An association with pancreatic cancer is less evident [20,246-249], but mutations in genes coding for DDR proteins (including CHEK2) in pancreatic cancer patients were associated with improved survival [250-253]. Germline CHEK2 variants were shown to protect against lung cancer, including in patients with a tobacco-related disease [134,254]. Besides solid tumors, an increased CHEK2 risk has been reported in patients with hematological malignancies [20,255-259].

Some of the analyzed tumor types are a conundrum evergreen for translational research and a nightmare for clinical geneticists. Ovarian cancer ranks among such recurrently queried tumors. With its poor prognosis and inferior treatment outcomes, it is clinically highly desirable to characterize the predisposition factors enabling tailored surveillance, to prevent and/or detect early ovarian cancer, or to start targeted therapy. All ovarian cancer patients are eligible for germline genetic testing. As ovarian cancer associates with breast cancer, the patients are analyzed by overlapping or identical NGS panels and thus ovarian cancer patients probably represent the largest cancer group explored for mutations in the CHEK2 gene just after breast cancer patients. However, despite many published results, the association of CHEK2 mutations with ovarian cancer (or its particular non-high-grade subtypes) can be neither confirmed nor rejected, and it illustrates the stalemate situation with the clinical interpretation of germline CHEK2 variants [115,260-263].

\section{Concluding Remarks and Future Directions}

The CHEK2 gene codes for checkpoint kinase CHK2, activated mainly in DDR. Substrates of activated CHK2 include many intracellular targets regulating numerous signaling pathways. However, the quantitative importance of CHK2 in these regulations in particular human tissues remains to be identified.

Pathogenic germline CHEK2 mutations rank among the most frequent alterations in various tumors. The association of germline CHEK2 variants has been confirmed for the most frequent gender-specific tumors, including breast and prostate. Despite the high probability of an association with several other cancers, including renal and thyroid cancer, there is no recommendation to prevent these tumors in CHEK2 carriers. Unfortunately, an association with numerous tumor types and subtypes remains uncertain so far. The major sources of this uncertainty include insufficient numbers of patients with a comprehensive CHEK2 mutation analysis (including CNV), deficient functional classification of CHEK2 VUS, and a lack of a precise use of geographically matched population controls for unequivocal 
evaluation of the association. The latter point disregarded by many studies is of particular importance if we assume a large population diversity of germline CHEK2 mutations worldwide, a high frequency of its germline alterations (comparable with that of $A T M$ for which the coding sequence is five times larger than that of the CHEK2 gene), and incomplete penetrance of CHEK2 mutations.

Funding: This research was funded by the Ministry of Health of the Czech Republic (grant number NV19-03-00279), to LS by Charles University project (SVV2019/260367), by Charles University project PROGRES Q28/LF1, and by the Academy of Sciences of the Czech Republic project Strategie AV21, Qualitas.

Acknowledgments: We would like to thank our colleagues for their valuable comments and support and Jan Flemr for editing and proofreading of the manuscript.

Conflicts of Interest: The authors declare no conflict of interest.

\section{References}

1. Pilleron, S.; Soto-Perez-de-Celis, E.; Vignat, J.; Ferlay, J.; Soerjomataram, I.; Bray, F.; Sarfati, D. Estimated global cancer incidence in the oldest adults in 2018 and projections to 2050. Int. J. Cancer 2020. [CrossRef] [PubMed]

2. Bray, F.; Ferlay, J.; Soerjomataram, I.; Siegel, R.L.; Torre, L.A.; Jemal, A. Global cancer statistics 2018: GLOBOCAN estimates of incidence and mortality worldwide for 36 cancers in 185 countries. CA Cancer J. Clin. 2018, 68, 394-424. [CrossRef] [PubMed]

3. Hanahan, D.; Weinberg, R.A. Hallmarks of cancer: The next generation. Cell 2011, 144, 646-674. [CrossRef] [PubMed]

4. Benada, J.; Macurek, L. Targeting the Checkpoint to Kill Cancer Cells. Biomolecules 2015, 5, $1912-1937$. [CrossRef]

5. Rahman, N. Realizing the promise of cancer predisposition genes. Nature 2014, 505, 302-308. [CrossRef]

6. Hyman, D.M.; Taylor, B.S.; Baselga, J. Implementing Genome-Driven Oncology. Cell 2017, 168, 584-599. [CrossRef]

7. Turnbull, C.; Sud, A.; Houlston, R.S. Cancer genetics, precision prevention and a call to action. Nat. Genet. 2018, 50, 1212-1218. [CrossRef]

8. Easton, D.F.; Pharoah, P.D.; Antoniou, A.C.; Tischkowitz, M.; Tavtigian, S.V.; Nathanson, K.L.; Devilee, P.; Meindl, A.; Couch, F.J.; Southey, M.; et al. Gene-panel sequencing and the prediction of breast-cancer risk. N. Engl. J. Med. 2015, 372, 2243-2257. [CrossRef]

9. Shah, P.D.; Nathanson, K.L. Application of Panel-Based Tests for Inherited Risk of Cancer. Annu. Rev. Genom. Hum. Genet. 2017, 18, 201-227. [CrossRef]

10. Kapoor, N.S.; Curcio, L.D.; Blakemore, C.A.; Bremner, A.K.; McFarland, R.E.; West, J.G.; Banks, K.C. Multigene Panel Testing Detects Equal Rates of Pathogenic BRCA1/2 Mutations and has a Higher Diagnostic Yield Compared to Limited BRCA1/2 Analysis Alone in Patients at Risk for Hereditary Breast Cancer. Ann. Surg. Oncol. 2015, 22, 3282-3288. [CrossRef]

11. Federici, G.; Soddu, S. Variants of uncertain significance in the era of high-throughput genome sequencing: A lesson from breast and ovary cancers. J. Exp. Clin. Cancer Res. 2020, 39, 46. [CrossRef] [PubMed]

12. Fackenthal, J.D.; Olopade, O.I. Breast cancer risk associated with BRCA1 and BRCA2 in diverse populations. Nat. Rev. Cancer 2007, 7, 937-948. [CrossRef] [PubMed]

13. Belman, S.; Parsons, M.T.; Spurdle, A.B.; Goldgar, D.E.; Feng, B.J. Considerations in assessing germline variant pathogenicity using cosegregation analysis. Genet. Med. 2020. [CrossRef] [PubMed]

14. Falck, J.; Mailand, N.; Syljuasen, R.G.; Bartek, J.; Lukas, J. The ATM-Chk2-Cdc25A checkpoint pathway guards against radioresistant DNA synthesis. Nature 2001, 410, 842-847. [CrossRef] [PubMed]

15. Bartek, J.; Lukas, J. Chk1 and Chk2 kinases in checkpoint control and cancer. Cancer Cell 2003, 3, 421-429. [CrossRef]

16. Matsuoka, S.; Huang, M.; Elledge, S.J. Linkage of ATM to Cell Cycle Regulation by the Chk2 Protein Kinase. Science 1998, 282, 1893-1897. [CrossRef]

17. Bartkova, J.; Horejsi, Z.; Koed, K.; Kramer, A.; Tort, F.; Zieger, K.; Guldberg, P.; Sehested, M.; Nesland, J.M.; Lukas, C.; et al. DNA damage response as a candidate anti-cancer barrier in early human tumorigenesis. Nature 2005, 434, 864-870. [CrossRef] 
18. Halazonetis, T.D.; Gorgoulis, V.G.; Bartek, J. An Oncogene-Induced DNA Damage Model for Cancer Development. Science 2008, 319, 1352-1355. [CrossRef]

19. Bell, D.W.; Varley, J.M.; Szydlo, T.E.; Kang, D.H.; Wahrer, D.C.; Shannon, K.E.; Lubratovich, M.; Verselis, S.J.; Isselbacher, K.J.; Fraumeni, J.F.; et al. Heterozygous germ line hCHK2 mutations in Li-Fraumeni syndrome. Science 1999, 286, 2528-2531. [CrossRef]

20. Cybulski, C.; Gorski, B.; Huzarski, T.; Masojc, B.; Mierzejewski, M.; Debniak, T.; Teodorczyk, U.; Byrski, T.; Gronwald, J.; Matyjasik, J.; et al. CHEK2 is a multiorgan cancer susceptibility gene. Am. J. Hum. Genet. 2004, 75, 1131-1135. [CrossRef]

21. Delimitsou, A.; Fostira, F.; Kalfakakou, D.; Apostolou, P.; Konstantopoulou, I.; Kroupis, C.; Papavassiliou, A.G.; Kleibl, Z.; Stratikos, E.; Voutsinas, G.E.; et al. Functional characterization of CHEK2 variants in a Saccharomyces cerevisiae system. Hum. Mutat. 2019, 40, 631-648. [CrossRef] [PubMed]

22. Caswell-Jin, J.L.; Gupta, T.; Hall, E.; Petrovchich, I.M.; Mills, M.A.; Kingham, K.E.; Koff, R.; Chun, N.M.; Levonian, P.; Lebensohn, A.P.; et al. Racial/ethnic differences in multiple-gene sequencing results for hereditary cancer risk. Genet. Med. 2018, 20, 234-239. [CrossRef] [PubMed]

23. Brown, A.L.; Lee, C.H.; Schwarz, J.K.; Mitiku, N.; Piwnica-Worms, H.; Chung, J.H. A human Cds1-related kinase that functions downstream of ATM protein in the cellular response to DNA damage. Proc. Natl. Acad. Sci. USA 1999, 96, 3745-3750. [CrossRef] [PubMed]

24. Chaturvedi, P.; Eng, W.K.; Zhu, Y.; Mattern, M.R.; Mishra, R.; Hurle, M.R.; Zhang, X.; Annan, R.S.; Lu, Q.; Faucette, L.F.; et al. Mammalian Chk2 is a downstream effector of the ATM-dependent DNA damage checkpoint pathway. Oncogene 1999, 18, 4047-4054. [CrossRef] [PubMed]

25. Melo, J.; Toczyski, D. A unified view of the DNA-damage checkpoint. Curr. Opin. Cell Biol. 2002, 14, $237-245$. [CrossRef]

26. Zoppoli, G.; Solier, S.; Reinhold, W.C.; Liu, H.; Connelly, J.W.; Monks, A.; Shoemaker, R.H.; Abaan, O.D.; Davis, S.R.; Meltzer, P.S.; et al. CHEK2 genomic and proteomic analyses reveal genetic inactivation or endogenous activation across the 60 cell lines of the US National Cancer Institute. Oncogene 2012, 31, 403-418. [CrossRef] [PubMed]

27. Tominaga, K.; Morisaki, H.; Kaneko, Y.; Fujimoto, A.; Tanaka, T.; Ohtsubo, M.; Hirai, M.; Okayama, H.; Ikeda, K.; Nakanishi, M. Role of human Cds1 (Chk2) kinase in DNA damage checkpoint and its regulation by p53. J. Biol. Chem. 1999, 274, 31463-31467. [CrossRef]

28. Staalesen, V.; Falck, J.; Geisler, S.; Bartkova, J.; Borresen-Dale, A.L.; Lukas, J.; Lillehaug, J.R.; Bartek, J.; Lonning, P.E. Alternative splicing and mutation status of CHEK2 in stage III breast cancer. Oncogene 2004. [CrossRef]

29. Matsui, T.; Katsuno, Y.; Inoue, T.; Fujita, F.; Joh, T.; Niida, H.; Murakami, H.; Itoh, M.; Nakanishi, M. Negative regulation of Chk2 expression by p53 is dependent on the CCAAT-binding transcription factor NF-Y. J. Biol. Chem. 2004, 279, 25093-25100. [CrossRef]

30. Williams, L.H.; Choong, D.; Johnson, S.A.; Campbell, I.G. Genetic and epigenetic analysis of CHEK2 in sporadic breast, colon, and ovarian cancers. Clin. Cancer Res. 2006, 12, 6967-6972. [CrossRef]

31. Sodha, N.; Williams, R.; Mangion, J.; Bullock, S.L.; Yuille, M.R.; Eeles, R.A.; Bell, D.W.; Wahrer, D.C.R.; Varley, J.M.; Haber, D.A. Screening hCHK2 for Mutations. Science 2000, 289, 359a. [CrossRef] [PubMed]

32. Munch, C.; Kirsch, S.; Fernandes, A.M.; Schempp, W. Evolutionary analysis of the highly dynamic CHEK2 duplicon in anthropoids. BMC Evol. Biol. 2008, 8, 269. [CrossRef] [PubMed]

33. Ahn, J.; Urist, M.; Prives, C. The Chk2 protein kinase. DNA Repair 2004, 3, 1039-1047. [CrossRef] [PubMed]

34. Li, J.; Williams, B.L.; Haire, L.F.; Goldberg, M.; Wilker, E.; Durocher, D.; Yaffe, M.B.; Jackson, S.P.; Smerdon, S.J. Structural and functional versatility of the FHA domain in DNA-damage signaling by the tumor suppressor kinase Chk2. Mol. Cell 2002, 9, 1045-1054. [CrossRef]

35. Cai, Z.; Chehab, N.H.; Pavletich, N.P. Structure and activation mechanism of the CHK2 DNA damage checkpoint kinase. Mol. Cell. 2009, 35, 818-829. [CrossRef]

36. Wybenga-Groot, L.E.; Ho, C.S.; Sweeney, F.D.; Ceccarelli, D.F.; McGlade, C.J.; Durocher, D.; Sicheri, F. Structural basis of Rad53 kinase activation by dimerization and activation segment exchange. Cell Signal 2014, 26, 1825-1836. [CrossRef]

37. Matsuoka, S.; Rotman, G.; Ogawa, A.; Shiloh, Y.; Tamai, K.; Elledge, S.J. Ataxia telangiectasia-mutated phosphorylates Chk2 in vivo and in vitro. Proc. Natl. Acad. Sci. USA 2000, 97, 10389-10394. [CrossRef] 
38. Ouchi, M.; Ouchi, T. Distinct DNA damage determines differential phosphorylation of Chk2. Cancer Biol. Ther. 2014, 15, 1700-1704. [CrossRef]

39. Zannini, L.; Lecis, D.; Lisanti, S.; Benetti, R.; Buscemi, G.; Schneider, C.; Delia, D. Karyopherin-alpha2 protein interacts with Chk2 and contributes to its nuclear import. J. Biol. Chem. 2003, 278, 42346-42351. [CrossRef]

40. Schwarz, J.K.; Lovly, C.M.; Piwnica-Worms, H. Regulation of the Chk2 Protein Kinase by Oligomerization-Mediated cis- and trans-Phosphorylation. Mol. Cancer Res. 2003, 1, 598-609.

41. Kurz, E.U.; Douglas, P.; Lees-Miller, S.P. Doxorubicin activates ATM-dependent phosphorylation of multiple downstream targets in part through the generation of reactive oxygen species. J. Biol. Chem. 2004, 279, 53272-53281. [CrossRef] [PubMed]

42. Kass, E.M.; Ahn, J.; Tanaka, T.; Freed-Pastor, W.A.; Keezer, S.; Prives, C. Stability of checkpoint kinase 2 is regulated via phosphorylation at serine 456. J. Biol. Chem. 2007, 282, 30311-30321. [CrossRef] [PubMed]

43. Gabant, G.; Lorphelin, A.; Nozerand, N.; Marchetti, C.; Bellanger, L.; Dedieu, A.; Quemeneur, E.; Alpha-Bazin, B. Autophosphorylated residues involved in the regulation of human chk2 in vitro. J. Mol. Biol. 2008, 380, 489-503. [CrossRef] [PubMed]

44. Oliver, A.W.; Paul, A.; Boxall, K.J.; Barrie, S.E.; Aherne, G.W.; Garrett, M.D.; Mittnacht, S.; Pearl, L.H. Trans-activation of the DNA-damage signalling protein kinase Chk2 by T-loop exchange. EMBO J. 2006, 25, 3179-3190. [CrossRef] [PubMed]

45. Wu, X.; Chen, J. Autophosphorylation of checkpoint kinase 2 at serine 516 is required for radiation-induced apoptosis. J. Biol. Chem. 2003, 278, 36163-36168. [CrossRef]

46. Blackford, A.N.; Jackson, S.P. ATM, ATR, and DNA-PK: The Trinity at the Heart of the DNA Damage Response. Mol. Cell 2017, 66, 801-817. [CrossRef] [PubMed]

47. Shang, Z.; Yu, L.; Lin, Y.F.; Matsunaga, S.; Shen, C.Y.; Chen, B.P. DNA-PKcs activates the Chk2-Brca1 pathway during mitosis to ensure chromosomal stability. Oncogenesis 2014, 3, e85. [CrossRef]

48. Aquino Perez, C.; Palek, M.; Stolarova, L.; von Morgen, P.; Macurek, L. Phosphorylation of PLK3 Is Controlled by Protein Phosphatase 6. Cells 2020, 9, 1506. [CrossRef]

49. Bahassiel, M.; Myer, D.L.; McKenney, R.J.; Hennigan, R.F.; Stambrook, P.J. Priming phosphorylation of Chk2 by polo-like kinase 3 (Plk3) mediates its full activation by ATM and a downstream checkpoint in response to DNA damage. Mutat. Res. 2006, 596, 166-176. [CrossRef]

50. Van Vugt, M.A.; Gardino, A.K.; Linding, R.; Ostheimer, G.J.; Reinhardt, H.C.; Ong, S.E.; Tan, C.S.; Miao, H.; Keezer, S.M.; Li, J.; et al. A mitotic phosphorylation feedback network connects Cdk1, Plk1, 53BP1, and Chk2 to inactivate the G(2)/M DNA damage checkpoint. PLoS Biol. 2010, 8, e1000287. [CrossRef]

51. Benada, J.; Burdová, K.; Lidak, T.; von Morgen, P.; Macurek, L. Polo-like kinase 1 inhibits DNA damage response during mitosis. Cell Cycle 2015, 14, 219-231. [CrossRef] [PubMed]

52. Chouinard, G.; Clement, I.; Lafontaine, J.; Rodier, F.; Schmitt, E. Cell cycle-dependent localization of CHK2 at centrosomes during mitosis. Cell Div. 2013, 8, 7. [CrossRef] [PubMed]

53. Oliva-Trastoy, M.; Berthonaud, V.; Chevalier, A.; Ducrot, C.; Marsolier-Kergoat, M.C.; Mann, C.; Leteurtre, F. The Wip1 phosphatase (PPM1D) antagonizes activation of the Chk2 tumour suppressor kinase. Oncogene 2007, 26, 1449-1458. [CrossRef] [PubMed]

54. Fujimoto, H.; Onishi, N.; Kato, N.; Takekawa, M.; Xu, X.Z.; Kosugi, A.; Kondo, T.; Imamura, M.; Oishi, I.; Yoda, A.; et al. Regulation of the antioncogenic Chk2 kinase by the oncogenic Wip1 phosphatase. Cell Death Differ. 2006, 13, 1170-1180. [CrossRef] [PubMed]

55. Freeman, A.K.; Dapic, V.; Monteiro, A.N. Negative regulation of CHK2 activity by protein phosphatase 2A is modulated by DNA damage. Cell Cycle 2010, 9, 736-747. [CrossRef] [PubMed]

56. Leroy, C.; Lee, S.E.; Vaze, M.B.; Ochsenbien, F.; Guerois, R.; Haber, J.E.; Marsolier-Kergoat, M.-C. PP2C Phosphatases Ptc2 and Ptc3 Are Required for DNA Checkpoint Inactivation after a Double-Strand Break. Mol. Cell 2003, 11, 827-835. [CrossRef]

57. Heikkinen, K.; Rapakko, K.; Karppinen, S.M.; Erkko, H.; Knuutila, S.; Lundan, T.; Mannermaa, A.; Borresen-Dale, A.L.; Borg, A.; Barkardottir, R.B.; et al. RAD50 and NBS1 are breast cancer susceptibility genes associated with genomic instability. Carcinogenesis 2006, 27, 1593-1599. [CrossRef]

58. Carlessi, L.; Buscemi, G.; Fontanella, E.; Delia, D. A protein phosphatase feedback mechanism regulates the basal phosphorylation of Chk2 kinase in the absence of DNA damage. Biochim. Biophys. Acta 2010, 1803, 1213-1223. [CrossRef] 
59. Bolton, K.L.; Ptashkin, R.N.; Gao, T.; Braunstein, L.; Devlin, S.M.; Kelly, D.; Patel, M.; Berthon, A.; Syed, A.; Yabe, M.; et al. Cancer therapy shapes the fitness landscape of clonal hematopoiesis. Nat. Genet. 2020. [CrossRef]

60. Bohgaki, M.; Hakem, A.; Halaby, M.J.; Bohgaki, T.; Li, Q.; Bissey, P.A.; Shloush, J.; Kislinger, T.; Sanchez, O.; Sheng, Y.; et al. The E3 ligase PIRH2 polyubiquitylates CHK2 and regulates its turnover. Cell Death Differ. 2013, 20, 812-822. [CrossRef]

61. Kass, E.M.; Poyurovsky, M.V.; Zhu, Y.; Prives, C. Mdm2 and PCAF increase Chk2 ubiquitination and degradation independently of their intrinsic E3 ligase activities. Cell Cycle 2009, 8, 430-437. [CrossRef] [PubMed]

62. Garcia-Limones, C.; Lara-Chica, M.; Jimenez-Jimenez, C.; Perez, M.; Moreno, P.; Munoz, E.; Calzado, M.A. CHK2 stability is regulated by the E3 ubiquitin ligase SIAH2. Oncogene 2016, 35, 4289-4301. [CrossRef] [PubMed]

63. Lovly, C.M.; Yan, L.; Ryan, C.E.; Takada, S.; Piwnica-Worms, H. Regulation of Chk2 ubiquitination and signaling through autophosphorylation of serine 379. Mol. Cell. Biol. 2008, 28, 5874-5885. [CrossRef] [PubMed]

64. Wang, L.; Yang, L.; Wang, C.; Zhao, W.; Ju, Z.; Zhang, W.; Shen, J.; Peng, Y.; An, C.; Luu, Y.T.; et al. Inhibition of the ATM/Chk2 axis promotes cGAS/STING signaling in ARID1A-deficient tumors. J. Clin. Investig. 2020. [CrossRef] [PubMed]

65. Zhang, D.; Zaugg, K.; Mak, T.W.; Elledge, S.J. A role for the deubiquitinating enzyme USP28 in control of the DNA-damage response. Cell 2006, 126, 529-542. [CrossRef]

66. Wu, J.; Chen, Y.; Geng, G.; Li, L.; Yin, P.; Nowsheen, S.; Li, Y.; Wu, C.; Liu, J.; Zhao, F.; et al. USP39 regulates DNA damage response and chemo-radiation resistance by deubiquitinating and stabilizing CHK2. Cancer Lett. 2019, 449, 114-124. [CrossRef]

67. Alves-Fernandes, D.K.; Jasiulionis, M.G. The Role of SIRT1 on DNA Damage Response and Epigenetic Alterations in Cancer. Int. J. Mol. Sci. 2019, 20, 3153. [CrossRef]

68. Seo, G.J.; Kim, S.E.; Lee, Y.M.; Lee, J.W.; Lee, J.R.; Hahn, M.J.; Kim, S.T. Determination of substrate specificity and putative substrates of Chk2 kinase. Biochem. Biophys. Res. Commun. 2003, 304, 339-343. [CrossRef]

69. Zannini, L.; Delia, D.; Buscemi, G. CHK2 kinase in the DNA damage response and beyond. J. Mol. Cell Biol. 2014, 6, 442-457. [CrossRef]

70. Paull, T.T. Mechanisms of ATM Activation. Annu. Rev. Biochem. 2015, 84, 711-738. [CrossRef]

71. Sulli, G.; Di Micco, R.; d'Adda di Fagagna, F. Crosstalk between chromatin state and DNA damage response in cellular senescence and cancer. Nat. Rev. Cancer 2012, 12, 709-720. [CrossRef] [PubMed]

72. Bartek, J.; Bartkova, J.; Lukas, J. DNA damage signalling guards against activated oncogenes and tumour progression. Oncogene 2007, 26, 7773-7779. [CrossRef] [PubMed]

73. Neizer-Ashun, F.; Bhattacharya, R. Reality CHEK: Understanding the biology and clinical potential of CHK1. Cancer Lett. 2020, 497, 202-211. [CrossRef] [PubMed]

74. Cheng, Q.; Chen, J. Mechanism of p53 stabilization by ATM after DNA damage. Cell Cycle 2010, 9, 472-478. [CrossRef] [PubMed]

75. Hirao, A.; Kong, Y.Y.; Matsuoka, S.; Wakeham, A.; Ruland, J.; Yoshida, H.; Liu, D.; Elledge, S.J.; Mak, T.W. DNA damage-induced activation of p53 by the checkpoint kinase Chk2. Science 2000, 287, 1824-1827. [CrossRef]

76. Chen, L.; Gilkes, D.M.; Pan, Y.; Lane, W.S.; Chen, J. ATM and Chk2-dependent phosphorylation of MDMX contribute to p53 activation after DNA damage. EMBO J. 2005, 24, 3411-3422. [CrossRef]

77. Bunz, F.; Dutriaux, A.; Lengauer, C.; Waldman, T.; Zhou, S.; Brown, J.P.; Sedivy, J.M.; Kinzler, K.W.; Vogelstein, B. Requirement for p53 and p21 to sustain G2 arrest after DNA damage. Science 1998, 282, 1497-1501. [CrossRef]

78. Waldman, T.; Kinzler, K.W.; Vogelstein, B. p21 is necessary for the p53-mediated G1 arrest in human cancer cells. Cancer Res. 1995, 55, 5187-5190.

79. Kastan, M.B.; Zhan, Q.; el-Deiry, W.S.; Carrier, F.; Jacks, T.; Walsh, W.V.; Plunkett, B.S.; Vogelstein, B.; Fornace, A.J., Jr. A mammalian cell cycle checkpoint pathway utilizing p53 and GADD45 is defective in ataxia-telangiectasia. Cell 1992, 71, 587-597. [CrossRef] 
80. Jack, M.T.; Woo, R.A.; Hirao, A.; Cheung, A.; Mak, T.W.; Lee, P.W. Chk2 is dispensable for p53-mediated G1 arrest but is required for a latent p53-mediated apoptotic response. Proc. Natl. Acad. Sci. USA 2002, 99, 9825-9829. [CrossRef]

81. Jallepalli, P.V.; Lengauer, C.; Vogelstein, B.; Bunz, F. The Chk2 tumor suppressor is not required for p53 responses in human cancer cells. J. Biol. Chem. 2003, 278, 20475-20479. [CrossRef] [PubMed]

82. Shaltiel, I.A.; Aprelia, M.; Saurin, A.T.; Chowdhury, D.; Kops, G.J.; Voest, E.E.; Medema, R.H. Distinct phosphatases antagonize the 533 response in different phases of the cell cycle. Proc. Natl. Acad. Sci. USA 2014, 111, 7313-7318. [CrossRef] [PubMed]

83. Hu, C.; Zhang, S.; Gao, X.; Gao, X.; Xu, X.; Lv, Y.; Zhang, Y.; Zhu, Z.; Zhang, C.; Li, Q.; et al. Roles of Kruppel-associated Box (KRAB)-associated Co-repressor KAP1 Ser-473 Phosphorylation in DNA Damage Response. J. Biol. Chem. 2012, 287, 18937-18952. [CrossRef] [PubMed]

84. Lee, D.H.; Goodarzi, A.A.; Adelmant, G.O.; Pan, Y.; Jeggo, P.A.; Marto, J.A.; Chowdhury, D. Phosphoproteomic analysis reveals that PP4 dephosphorylates KAP-1 impacting the DNA damage response. EMBO J. 2012, 31, 2403-2415. [CrossRef] [PubMed]

85. Stevens, C.; Smith, L.; La Thangue, N.B. Chk2 activates E2F-1 in response to DNA damage. Nat. Cell Biol. 2003, 5, 401-409. [CrossRef]

86. Donzelli, M.; Draetta, G.F. Regulating mammalian checkpoints through Cdc25 inactivation. EMBO Rep. 2003, 4, 671-677. [CrossRef]

87. Chen, J. The Cell-Cycle Arrest and Apoptotic Functions of p53 in Tumor Initiation and Progression. Cold Spring Harb. Perspect. Med. 2016, 6, a026104. [CrossRef]

88. Peng, C.Y.; Graves, P.R.; Thoma, R.S.; Wu, Z.; Shaw, A.S.; Piwnica-Worms, H. Mitotic and G2 checkpoint control: Regulation of 14-3-3 protein binding by phosphorylation of Cdc25C on serine-216. Science 1997, 277, 1501-1505. [CrossRef]

89. Yang, S.; Kuo, C.; Bisi, J.E.; Kim, M.K. PML-dependent apoptosis after DNA damage is regulated by the checkpoint kinase hCds1/Chk2. Nat. Cell Biol. 2002, 4, 865-870. [CrossRef]

90. Di Masi, A.; Cilli, D.; Berardinelli, F.; Talarico, A.; Pallavicini, I.; Pennisi, R.; Leone, S.; Antoccia, A.; Noguera, N.I.; Lo-Coco, F.; et al. PML nuclear body disruption impairs DNA double-strand break sensing and repair in APL. Cell Death Dis. 2016, 7, e2308. [CrossRef]

91. Yang, S.; Jeong, J.H.; Brown, A.L.; Lee, C.H.; Pandolfi, P.P.; Chung, J.H.; Kim, M.K. Promyelocytic leukemia activates Chk2 by mediating Chk2 autophosphorylation. J. Biol. Chem. 2006, 281, 26645-26654. [CrossRef] [PubMed]

92. Zhang, J.; Willers, H.; Feng, Z.; Ghosh, J.C.; Kim, S.; Weaver, D.T.; Chung, J.H.; Powell, S.N.; Xia, F. Chk2 phosphorylation of BRCA1 regulates DNA double-strand break repair. Mol. Cell Biol. 2004, 24, 708-718. [CrossRef] [PubMed]

93. Lee, J.S.; Collins, K.M.; Brown, A.L.; Lee, C.H.; Chung, J.H. hCds1-mediated phosphorylation of BRCA1 regulates the DNA damage response. Nature 2000, 404, 201-204. [CrossRef] [PubMed]

94. Petsalaki, E.; Zachos, G. DNA damage response proteins regulating mitotic cell division: Double agents preserving genome stability. FEBS J. 2020, 287, 1700-1721. [CrossRef] [PubMed]

95. Sankaran, S.; Starita, L.M.; Groen, A.C.; Ko, M.J.; Parvin, J.D. Centrosomal microtubule nucleation activity is inhibited by BRCA1-dependent ubiquitination. Mol. Cell Biol. 2005, 25, 8656-8668. [CrossRef] [PubMed]

96. Chabalier-Taste, C.; Racca, C.; Dozier, C.; Larminat, F. BRCA1 is regulated by Chk2 in response to spindle damage. Biochim. Biophys. Acta 2008, 1783, 2223-2233. [CrossRef]

97. Stolz, A.; Ertych, N.; Bastians, H. Tumor suppressor CHK2: Regulator of DNA damage response and mediator of chromosomal stability. Clin. Cancer Res. 2011, 17, 401-405. [CrossRef]

98. Nai, S.; Shi, Y.; Ru, H.; Ding, Y.; Geng, Q.; Li, Z.; Dong, M.Q.; Xu, X.; Li, J. Chk2-dependent phosphorylation of myosin phosphatase targeting subunit 1 (MYPT1) regulates centrosome maturation. Cell Cycle 2019, 18, 2651-2659. [CrossRef]

99. Guo, Q.Q.; Wang, S.S.; Zhang, S.S.; Xu, H.D.; Li, X.M.; Guan, Y.; Yi, F.; Zhou, T.T.; Jiang, B.; Bai, N.; et al. ATM-CHK2-Beclin 1 axis promotes autophagy to maintain ROS homeostasis under oxidative stress. EMBO J. 2020, 39, e103111. [CrossRef]

100. Chen, Y.; Wu, J.; Liang, G.; Geng, G.; Zhao, F.; Yin, P.; Nowsheen, S.; Wu, C.; Li, Y.; Li, L.; et al. CHK2-FOXK axis promotes transcriptional control of autophagy programs. Sci. Adv. 2020, 6, eaax5819. [CrossRef] 
101. Takai, H.; Naka, K.; Okada, Y.; Watanabe, M.; Harada, N.; Saito, S.; Anderson, C.W.; Appella, E.; Nakanishi, M.; Suzuki, H.; et al. Chk2-deficient mice exhibit radioresistance and defective p53-mediated transcription. EMBO J. 2002, 21, 5195-5205. [CrossRef] [PubMed]

102. Niida, H.; Murata, K.; Shimada, M.; Ogawa, K.; Ohta, K.; Suzuki, K.; Fujigaki, H.; Khaw, A.K.; Banerjee, B.; Hande, M.P.; et al. Cooperative functions of $\mathrm{Chk1}$ and $\mathrm{Chk} 2$ reduce tumour susceptibility in vivo. EMBO J. 2010, 29, 3558-3570. [CrossRef] [PubMed]

103. Paperna, T.; Sharon-Shwartzman, N.; Kurolap, A.; Goldberg, Y.; Moustafa, N.; Carasso, Y.; Feinstien, M.; Mory, A.; Reznick-Levi, G.; Gonzaga-Jauregui, C.; et al. Homozygosity for CHEK2 p.Gly167Arg leads to a unique cancer syndrome with multiple complex chromosomal translocations in peripheral blood karyotype. J. Med. Genet. 2019. [CrossRef]

104. Rainville, I.; Hatcher, S.; Rosenthal, E.; Larson, K.; Bernhisel, R.; Meek, S.; Gorringe, H.; Mundt, E.; Manley, S. High risk of breast cancer in women with biallelic pathogenic variants in CHEK2. Breast Cancer Res. Treat 2020. [CrossRef] [PubMed]

105. Van Jaarsveld, M.T.M.; Deng, D.; Ordoñez-Rueda, D.; Paulsen, M.; Wiemer, E.A.C.; Zi, Z. Cell-type-specific role of CHK2 in mediating DNA damage-induced G2 cell cycle arrest. Oncogenesis 2020, 9, 35. [CrossRef]

106. Wu, X.; Webster, S.R.; Chen, J. Characterization of tumor-associated Chk2 mutations. J. Biol. Chem. 2001, 276, 2971-2974. [CrossRef]

107. Allinen, M.; Huusko, P.; Mantyniemi, S.; Launonen, V.; Winqvist, R. Mutation analysis of the CHK2 gene in families with hereditary breast cancer. Br. J. Cancer 2001, 85, 209-212. [CrossRef]

108. Bougeard, G.; Limacher, J.M.; Martin, C.; Charbonnier, F.; Killian, A.; Delattre, O.; Longy, M.; Jonveaux, P.; Fricker, J.P.; Stoppa-Lyonnet, D.; et al. Detection of 11 germline inactivating TP53 mutations and absence of TP63 and HCHK2 mutations in 17 French families with Li-Fraumeni or Li-Fraumeni-like syndrome. J. Med. Genet. 2001, 38, 253-257. [CrossRef]

109. Sodha, N.; Houlston, R.S.; Bullock, S.; Yuille, M.A.; Chu, C.; Turner, G.; Eeles, R.A. Increasing evidence that germline mutations in CHEK2 do not cause Li-Fraumeni syndrome. Hum. Mutat. 2002, 20, 460-462. [CrossRef]

110. Vahteristo, P.; Bartkova, J.; Eerola, H.; Syrjakoski, K.; Ojala, S.; Kilpivaara, O.; Tamminen, A.; Kononen, J.; Aittomaki, K.; Heikkila, P.; et al. A CHEK2 genetic variant contributing to a substantial fraction of familial breast cancer. Am. J. Hum. Genet. 2002, 71, 432-438. [CrossRef]

111. Siddiqui, R.; Onel, K.; Facio, F.; Nafa, K.; Diaz, L.R.; Kauff, N.; Huang, H.; Robson, M.; Ellis, N.; Offit, K. The TP53 mutational spectrum and frequency of CHEK2*1100delC in Li-Fraumeni-like kindreds. Fam. Cancer 2005, 4, 177-181. [CrossRef] [PubMed]

112. Hogervorst, F.B.; Cornelis, R.S.; Bout, M.; van Vliet, M.; Oosterwijk, J.C.; Olmer, R.; Bakker, B.; Klijn, J.G.; Vasen, H.F.; Meijers-Heijboer, H.; et al. Rapid detection of BRCA1 mutations by the protein truncation test. Nat. Genet. 1995, 10, 208-212. [CrossRef] [PubMed]

113. Aloraifi, F.; McCartan, D.; McDevitt, T.; Green, A.J.; Bracken, A.; Geraghty, J. Protein-truncating variants in moderate-risk breast cancer susceptibility genes: A meta-analysis of high-risk case-control screening studies. Cancer Genet. 2015, 208, 455-463. [CrossRef] [PubMed]

114. Sutcliffe, E.G.; Stettner, A.R.; Miller, S.A.; Solomon, S.R.; Marshall, M.L.; Roberts, M.E.; Susswein, L.R.; Arvai, K.J.; Klein, R.T.; Murphy, P.D.; et al. Differences in cancer prevalence among CHEK2 carriers identified via multi-gene panel testing. Cancer Genet. 2020, 246-247, 12-17. [CrossRef]

115. Kleiblova, P.; Stolarova, L.; Krizova, K.; Lhota, F.; Hojny, J.; Zemankova, P.; Havranek, O.; Vocka, M.; Cerna, M.; Lhotova, K.; et al. Identification of deleterious germline CHEK2 mutations and their association with breast and ovarian cancer. Int. J. Cancer. J. Int. Cancer 2019. [CrossRef]

116. Apostolou, P.; Fostira, F.; Mollaki, V.; Delimitsou, A.; Vlassi, M.; Pentheroudakis, G.; Faliakou, E.; Kollia, P.; Fountzilas, G.; Yannoukakos, D.; et al. Characterization and prevalence of two novel CHEK2 large deletions in Greek breast cancer patients. J. Hum. Genet. 2018, 63, 877-886. [CrossRef]

117. Soukupova, J.; Zemankova, P.; Kleiblova, P.; Janatova, M.; Kleibl, Z. CZECANCA: CZEch CAncer paNel for Clinical Application- Design and Optimization of the Targeted Sequencing Panel for the Identification of Cancer Susceptibility in High-risk Individuals from the Czech Republic. Klin. Onkol. 2016, 29 (Suppl. 1), S46-S54. [CrossRef] 
118. Pritchard, C.C.; Mateo, J.; Walsh, M.F.; De Sarkar, N.; Abida, W.; Beltran, H.; Garofalo, A.; Gulati, R.; Carreira, S.; Eeles, R.; et al. Inherited DNA-Repair Gene Mutations in Men with Metastatic Prostate Cancer. N. Engl. J. Med. 2016, 375, 443-453. [CrossRef]

119. Young, E.L.; Feng, B.J.; Stark, A.W.; Damiola, F.; Durand, G.; Forey, N.; Francy, T.C.; Gammon, A.; Kohlmann, W.K.; Kaphingst, K.A.; et al. Multigene testing of moderate-risk genes: Be mindful of the missense. J. Med. Genet. 2016, 53, 366-376. [CrossRef]

120. Manoukian, S.; Peissel, B.; Frigerio, S.; Lecis, D.; Bartkova, J.; Roversi, G.; Radice, P.; Bartek, J.; Delia, D. Two new CHEK2 germ-line variants detected in breast cancer/sarcoma families negative for BRCA1, BRCA2, and TP53 gene mutations. Breast Cancer Res. Treat 2011, 130, 207-215. [CrossRef]

121. Bell, D.W.; Kim, S.H.; Godwin, A.K.; Schiripo, T.A.; Harris, P.L.; Haserlat, S.M.; Wahrer, D.C.; Haiman, C.A.; Daly, M.B.; Niendorf, K.B.; et al. Genetic and functional analysis of CHEK2 (CHK2) variants in multiethnic cohorts. Int. J. Cancer 2007, 121, 2661-2667. [CrossRef] [PubMed]

122. Desrichard, A.; Bidet, Y.; Uhrhammer, N.; Bignon, Y.J. CHEK2 contribution to hereditary breast cancer in non-BRCA families. Breast Cancer Res. 2011, 13, R119. [CrossRef] [PubMed]

123. Roeb, W.; Higgins, J.; King, M.C. Response to DNA damage of CHEK2 missense mutations in familial breast cancer. Hum. Mol. Genet. 2012, 21, 2738-2744. [CrossRef]

124. Tischkowitz, M.D.; Yilmaz, A.; Chen, L.Q.; Karyadi, D.M.; Novak, D.; Kirchhoff, T.; Hamel, N.; Tavtigian, S.V.; Kolb, S.; Bismar, T.A.; et al. Identification and characterization of novel SNPs in CHEK2 in Ashkenazi Jewish men with prostate cancer. Cancer Lett. 2008, 270, 173-180. [CrossRef] [PubMed]

125. Shaag, A.; Walsh, T.; Renbaum, P.; Kirchhoff, T.; Nafa, K.; Shiovitz, S.; Mandell, J.B.; Welcsh, P.; Lee, M.K.; Ellis, N.; et al. Functional and genomic approaches reveal an ancient CHEK2 allele associated with breast cancer in the Ashkenazi Jewish population. Hum. Mol. Genet. 2005, 14, 555-563. [CrossRef]

126. Hauke, J.; Horvath, J.; Gross, E.; Gehrig, A.; Honisch, E.; Hackmann, K.; Schmidt, G.; Arnold, N.; Faust, U.; Sutter, C.; et al. Gene panel testing of 5589 BRCA1/2-negative index patients with breast cancer in a routine diagnostic setting: Results of the German Consortium for Hereditary Breast and Ovarian Cancer. Cancer Med. 2018, 7, 1349-1358. [CrossRef]

127. Lhota, F.; Zemankova, P.; Kleiblova, P.; Soukupova, J.; Vocka, M.; Stranecky, V.; Janatova, M.; Hartmannova, H.; Hodanova, K.; Kmoch, S.; et al. Hereditary truncating mutations of DNA repair and other genes in BRCA1/BRCA2/PALB2-negatively tested breast cancer patients. Clin. Genet. 2016, 90, 324-333. [CrossRef]

128. Kurian, A.W.; Ward, K.C.; Howlader, N.; Deapen, D.; Hamilton, A.S.; Mariotto, A.; Miller, D.; Penberthy, L.S.; Katz, S.J. Genetic Testing and Results in a Population-Based Cohort of Breast Cancer Patients and Ovarian Cancer Patients. J. Clin. Oncol. 2019. [CrossRef]

129. Kleibl, Z.; Novotny, J.; Bezdickova, D.; Malik, R.; Kleiblova, P.; Foretova, L.; Petruzelka, L.; Ilencikova, D.; Cinek, P.; Pohlreich, P. The CHEK2 c.1100delC germline mutation rarely contributes to breast cancer development in the Czech Republic. Breast Cancer Res. Treat 2005, 90, 165-167. [CrossRef]

130. Caligo, M.A.; Agata, S.; Aceto, G.; Crucianelli, R.; Manoukian, S.; Peissel, B.; Scaini, M.C.; Sensi, E.; Veschi, S.; Cama, A.; et al. The CHEK2 c.1100delC mutation plays an irrelevant role in breast cancer predisposition in Italy. Hum. Mutat. 2004, 24, 100-101. [CrossRef]

131. Fachal, L.; Santamarina, M.; Blanco, A.; Carracedo, A.; Vega, A. CHEK2 c.1100delC mutation among non-BRCA1/2 Spanish hereditary breast cancer families. Clin. Transl. Oncol. 2013, 15, 164-165. [CrossRef] [PubMed]

132. Apostolou, P.; Fostira, F.; Papamentzelopoulou, M.; Michelli, M.; Panopoulos, C.; Fountzilas, G.; Konstantopoulou, I.; Voutsinas, G.E.; Yannoukakos, D. CHEK2 c.1100delC allele is rarely identified in Greek breast cancer cases. Cancer Genet. 2015, 208, 129-134. [CrossRef] [PubMed]

133. Irmejs, A.; Miklasevics, E.; Boroschenko, V.; Gardovskis, A.; Vanags, A.; Melbarde-Gorkusa, I.; Bitina, M.; Suchy, J.; Gardovskis, J. Pilot study on low penetrance breast and colorectal cancer predisposition markers in latvia. Hered. Cancer Clin. Pract. 2006, 4, 48-51. [CrossRef] [PubMed]

134. Brennan, P.; McKay, J.; Moore, L.; Zaridze, D.; Mukeria, A.; Szeszenia-Dabrowska, N.; Lissowska, J.; Rudnai, P.; Fabianova, E.; Mates, D.; et al. Uncommon CHEK2 mis-sense variant and reduced risk of tobacco-related cancers: Case control study. Hum. Mol. Genet. 2007, 16, 1794-1801. [CrossRef] [PubMed]

135. Bermisheva, M.A.; Takhirova, Z.R.; Bogdanova, N.; Khusnutdinova, E.K. Frequency of CHEK2 gene mutations in breast cancer patients from Republic of Bashkortostan. Mol. Biol. 2014, 48, 46-51. [CrossRef] 
136. Kleibl, Z.; Havranek, O.; Novotny, J.; Kleiblova, P.; Soucek, P.; Pohlreich, P. Analysis of CHEK2 FHA domain in Czech patients with sporadic breast cancer revealed distinct rare genetic alterations. Breast Cancer Res. Treat 2008, 112, 159-164. [CrossRef]

137. Kaufman, B.; Laitman, Y.; Gronwald, J.; Winqvist, R.; Irmejs, A.; Lubinski, J.; Pylkas, K.; Gardovskis, J.; Miklasevics, E.; Friedman, E. Haplotypes of the I157T CHEK2 germline mutation in ethnically diverse populations. Fam. Cancer 2009, 8, 473-478. [CrossRef]

138. Walsh, T.; Casadei, S.; Coats, K.H.; Swisher, E.; Stray, S.M.; Higgins, J.; Roach, K.C.; Mandell, J.; Lee, M.K.; Ciernikova, S.; et al. Spectrum of mutations in BRCA1, BRCA2, CHEK2, and TP53 in families at high risk of breast cancer. JAMA J. Am. Med. Assoc. 2006, 295, 1379-1388. [CrossRef]

139. Cybulski, C.; Huzarski, T.; Byrski, T.; Gronwald, J.; Debniak, T.; Jakubowska, A.; Gorski, B.; Wokolorczyk, D.; Masojc, B.; Narod, S.A.; et al. Estrogen receptor status in CHEK2-positive breast cancers: Implications for chemoprevention. Clin Genet. 2009, 75, 72-78. [CrossRef]

140. Plonis, J.; Kalniete, D.; Nakazawa-Miklasevica, M.; Irmejs, A.; Vjaters, E.; Gardovskis, J.; Miklasevics, E. The CHEK2 del5395 is a founder mutation without direct effects for cancer risk in the latvian population. Balk. J. Med. Genet. 2015, 18, 33-36. [CrossRef]

141. Sun, J.; Meng, H.; Yao, L.; Lv, M.; Bai, J.; Zhang, J.; Wang, L.; Ouyang, T.; Li, J.; Wang, T.; et al. Germline Mutations in Cancer Susceptibility Genes in a Large Series of Unselected Breast Cancer Patients. Clin. Cancer Res. 2017, 23, 6113-6119. [CrossRef] [PubMed]

142. Fan, Z.; Ouyang, T.; Li, J.; Wang, T.; Fan, Z.; Fan, T.; Lin, B.; Xu, Y.; Xie, Y. Identification and analysis of CHEK2 germline mutations in Chinese BRCA1/2-negative breast cancer patients. Breast Cancer Res. Treat 2018, 169, 59-67. [CrossRef] [PubMed]

143. Zeng, C.; Guo, X.; Wen, W.; Shi, J.; Long, J.; Cai, Q.; Shu, X.O.; Xiang, Y.; Zheng, W. Evaluation of pathogenetic mutations in breast cancer predisposition genes in population-based studies conducted among Chinese women. Breast Cancer Res. Treat 2020, 181, 465-473. [CrossRef] [PubMed]

144. Momozawa, Y.; Iwasaki, Y.; Hirata, M.; Liu, X.; Kamatani, Y.; Takahashi, A.; Sugano, K.; Yoshida, T.; Murakami, Y.; Matsuda, K.; et al. Germline Pathogenic Variants in 7636 Japanese Patients With Prostate Cancer and 12366 Controls. J. Natl. Cancer Inst. 2020, 112, 369-376. [CrossRef]

145. Momozawa, Y.; Iwasaki, Y.; Parsons, M.T.; Kamatani, Y.; Takahashi, A.; Tamura, C.; Katagiri, T.; Yoshida, T.; Nakamura, S.; Sugano, K.; et al. Germline pathogenic variants of 11 breast cancer genes in 7,051 Japanese patients and 11,241 controls. Nat. Commun. 2018, 9, 4083. [CrossRef]

146. Fostira, F.; Kostantopoulou, I.; Apostolou, P.; Papamentzelopoulou, M.S.; Papadimitriou, C.; Faliakou, E.; Christodoulou, C.; Boukovinas, I.; Razis, E.; Tryfonopoulos, D.; et al. One in three highly selected Greek patients with breast cancer carries a loss-of-function variant in a cancer susceptibility gene. J. Med. Genet. 2020, 57, 53-61. [CrossRef]

147. Kurian, A.W.; Bernhisel, R.; Larson, K.; Caswell-Jin, J.L.; Shadyab, A.H.; Ochs-Balcom, H.; Stefanick, M.L. Prevalence of Pathogenic Variants in Cancer Susceptibility Genes Among Women With Postmenopausal Breast Cancer. JAMA J. Am. Med. Assoc. 2020, 323, 995-997. [CrossRef]

148. Rogoża-Janiszewska, E.; Malińska, K.; Cybulski, C.; Jakubowska, A.; Gronwald, J.; Huzarski, T.; Lener, M.; Górski, B.; Kluźniak, W.; Rudnicka, H.; et al. Prevalence of Recurrent Mutations Predisposing to Breast Cancer in Early-Onset Breast Cancer Patients from Poland. Cancers 2020, 12, 2321. [CrossRef]

149. Cybulski, C.; Kluźniak, W.; Huzarski, T.; Wokołorczyk, D.; Kashyap, A.; Rusak, B.; Stempa, K.; Gronwald, J.; Szymiczek, A.; Bagherzadeh, M.; et al. The spectrum of mutations predisposing to familial breast cancer in Poland. Int. J. Cancer 2019, 145, 3311-3320. [CrossRef]

150. Nurmi, A.; Muranen, T.A.; Pelttari, L.M.; Kiiski, J.I.; Heikkinen, T.; Lehto, S.; Kallioniemi, A.; Schleutker, J.; Butzow, R.; Blomqvist, C.; et al. Recurrent moderate-risk mutations in Finnish breast and ovarian cancer patients. Int. J. Cancer 2019. [CrossRef]

151. Girard, E.; Eon-Marchais, S.; Olaso, R.; Renault, A.L.; Damiola, F.; Dondon, M.G.; Barjhoux, L.; Goidin, D.; Meyer, V.; Le Gal, D.; et al. Familial breast cancer and DNA repair genes: Insights into known and novel susceptibility genes from the GENESIS study, and implications for multigene panel testing. Int. J. Cancer 2019, 144, 1962-1974. [CrossRef] [PubMed]

152. Decker, B.; Allen, J.; Luccarini, C.; Pooley, K.A.; Shah, M.; Bolla, M.K.; Wang, Q.; Ahmed, S.; Baynes, C.; Conroy, D.M.; et al. Rare, protein-truncating variants in ATM, CHEK2 and PALB2, but not XRCC2, are associated with increased breast cancer risks. J. Med. Genet. 2017, 54, 732-741. [CrossRef] [PubMed] 
153. Slavin, T.P.; Maxwell, K.N.; Lilyquist, J.; Vijai, J.; Neuhausen, S.L.; Hart, S.N.; Ravichandran, V.; Thomas, T.; Maria, A.; Villano, D.; et al. The contribution of pathogenic variants in breast cancer susceptibility genes to familial breast cancer risk. NPJ Breast Cancer 2017, 3, 22. [CrossRef] [PubMed]

154. Couch, F.J.; Shimelis, H.; Hu, C.; Hart, S.N.; Polley, E.C.; Na, J.; Hallberg, E.; Moore, R.; Thomas, A.; Lilyquist, J.; et al. Associations Between Cancer Predisposition Testing Panel Genes and Breast Cancer. JAMA Oncol. 2017, 3, 1190-1196. [CrossRef] [PubMed]

155. Schmidt, M.K.; Hogervorst, F.; van Hien, R.; Cornelissen, S.; Broeks, A.; Adank, M.A.; Meijers, H.; Waisfisz, Q.; Hollestelle, A.; Schutte, M.; et al. Age-and Tumor Subtype-Specific Breast Cancer Risk Estimates for CHEK2*1100delC Carriers. J. Clin. Oncol. 2016, 34, 2750-2760. [CrossRef] [PubMed]

156. Naslund-Koch, C.; Nordestgaard, B.G.; Bojesen, S.E. Increased Risk for Other Cancers in Addition to Breast Cancer for CHEK2*1100delC Heterozygotes Estimated From the Copenhagen General Population Study. J. Clin. Oncol. 2016, 34, 1208-1216. [CrossRef]

157. Southey, M.C.; Goldgar, D.E.; Winqvist, R.; Pylkas, K.; Couch, F.; Tischkowitz, M.; Foulkes, W.D.; Dennis, J.; Michailidou, K.; van Rensburg, E.J.; et al. PALB2, CHEK2 and ATM rare variants and cancer risk: Data from COGS. J. Med. Genet. 2016, 53, 800-811. [CrossRef]

158. Liu, Y.; Liao, J.; Xu, Y.; Chen, W.; Liu, D.; Ouyang, T.; Li, J.; Wang, T.; Fan, Z.; Fan, T.; et al. A recurrent CHEK2 p.H371Y mutation is associated with breast cancer risk in Chinese women. Hum. Mutat. 2011, 32, 1000-1003. [CrossRef]

159. Cybulski, C.; Wokolorczyk, D.; Jakubowska, A.; Huzarski, T.; Byrski, T.; Gronwald, J.; Masojc, B.; Deebniak, T.; Gorski, B.; Blecharz, P.; et al. Risk of breast cancer in women with a CHEK2 mutation with and without a family history of breast cancer. J. Clin. Oncol. 2011, 29, 3747-3752. [CrossRef]

160. Le Calvez-Kelm, F.; Lesueur, F.; Damiola, F.; Vallee, M.; Voegele, C.; Babikyan, D.; Durand, G.; Forey, N.; McKay-Chopin, S.; Robinot, N.; et al. Rare, evolutionarily unlikely missense substitutions in CHEK2 contribute to breast cancer susceptibility: Results from a breast cancer family registry case-control mutation-screening study. Breast Cancer Res. 2011, 13, R6. [CrossRef]

161. Fletcher, O.; Johnson, N.; Dos Santos Silva, I.; Kilpivaara, O.; Aittomaki, K.; Blomqvist, C.; Nevanlinna, H.; Wasielewski, M.; Meijers-Heijerboer, H.; Broeks, A.; et al. Family history, genetic testing, and clinical risk prediction: Pooled analysis of CHEK2 1100delC in 1,828 bilateral breast cancers and 7030 controls. Cancer Epidemiol. Biomark. Prev. 2009, 18, 230-234. [CrossRef] [PubMed]

162. Weischer, M.; Bojesen, S.E.; Tybjaerg-Hansen, A.; Axelsson, C.K.; Nordestgaard, B.G. Increased risk of breast cancer associated with CHEK2*1100delC. J. Clin. Oncol. 2007, 25, 57-63. [CrossRef] [PubMed]

163. Cybulski, C.; Gorski, B.; Huzarski, T.; Byrski, T.; Gronwald, J.; Debniak, T.; Wokolorczyk, D.; Jakubowska, A.; Kowalska, E.; Oszurek, O.; et al. CHEK2-positive breast cancers in young Polish women. Clin. Cancer Res. 2006, 12, 4832-4835. [CrossRef] [PubMed]

164. Chekmariova, E.V.; Sokolenko, A.P.; Buslov, K.G.; Iyevleva, A.G.; Ulibina, Y.M.; Rozanov, M.E.; Mitiushkina, N.V.; Togo, A.V.; Matsko, D.E.; Voskresenskiy, D.A.; et al. CHEK2 1100delC mutation is frequent among Russian breast cancer patients. Breast Cancer Res. Treat 2006, 100, 99-102. [CrossRef] [PubMed]

165. Dufault, M.R.; Betz, B.; Wappenschmidt, B.; Hofmann, W.; Bandick, K.; Golla, A.; Pietschmann, A.; Nestle-Kramling, C.; Rhiem, K.; Huttner, C.; et al. Limited relevance of the CHEK2 gene in hereditary breast cancer. Int. J. Cancer 2004, 110, 320-325. [CrossRef] [PubMed]

166. Consortium, C.B.C.C.-C. CHEK2* $1100 \mathrm{delC}$ and susceptibility to breast cancer: A collaborative analysis involving 10,860 breast cancer cases and 9,065 controls from 10 studies. Am. J. Hum. Genet. 2004, 74, 1175-1182. [CrossRef]

167. Meijers-Heijboer, H.; van den, O.A.; Klijn, J.; Wasielewski, M.; de Snoo, A.; Oldenburg, R.; Hollestelle, A.; Houben, M.; Crepin, E.; Veghel-Plandsoen, M.; et al. Low-penetrance susceptibility to breast cancer due to CHEK2 $\left(^{*}\right) 1100 \mathrm{delC}$ in noncarriers of BRCA1 or BRCA2 mutations. Nat. Genet. 2002, 31, 55-59.

168. Liang, M.; Zhang, Y.; Sun, C.; Rizeq, F.K.; Min, M.; Shi, T.; Sun, Y. Association between CHEK2*1100delC and Breast Cancer: A Systematic Review and Meta-Analysis. Mol. Diagn. 2018, 22, 397-407. [CrossRef]

169. Hallamies, S.; Pelttari, L.M.; Poikonen-Saksela, P.; Jekunen, A.; Jukkola-Vuorinen, A.; Auvinen, P.; Blomqvist, C.; Aittomaki, K.; Mattson, J.; Nevanlinna, H. CHEK2 c.1100delC mutation is associated with an increased risk for male breast cancer in Finnish patient population. BMC Cancer 2017, 17, 620. [CrossRef] 
170. Wasielewski, M.; den Bakker, M.A.; van den, O.A.; Meijer-van Gelder, M.E.; Portengen, H.; Klijn, J.G.; Meijers-Heijboer, H.; Foekens, J.A.; Schutte, M. CHEK2 1100delC and male breast cancer in the Netherlands. Breast Cancer Res. Treat. 2009, 116, 397-400. [CrossRef]

171. Yang, Y.; Shu, X.; Shu, X.O.; Bolla, M.K.; Kweon, S.S.; Cai, Q.; Michailidou, K.; Wang, Q.; Dennis, J.; Park, B.; et al. Re-evaluating genetic variants identified in candidate gene studies of breast cancer risk using data from nearly 280,000 women of Asian and European ancestry. EBioMedicine 2019, 48, 203-211. [CrossRef]

172. Han, F.F.; Guo, C.L.; Liu, L.H. The effect of CHEK2 variant I157T on cancer susceptibility: Evidence from a meta-analysis. DNA Cell Biol. 2013, 32, 329-335. [CrossRef]

173. Liu, C.; Wang, Y.; Wang, Q.S.; Wang, Y.J. The CHEK2 I157T variant and breast cancer susceptibility: A systematic review and meta-analysis. Asian Pac. J. Cancer Prev. APJCP 2012, 13, 1355-1360. [CrossRef]

174. Yang, Y.; Zhang, F.; Wang, Y.; Liu, S.C. CHEK2 1100delC variant and breast cancer risk in Caucasians: A meta-analysis based on 25 studies with 29,154 cases and 37,064 controls. Asian Pac. J. Cancer Prev. 2012, 13, 3501-3505. [CrossRef]

175. Zhang, B.; Beeghly-Fadiel, A.; Long, J.; Zheng, W. Genetic variants associated with breast-cancer risk: Comprehensive research synopsis, meta-analysis, and epidemiological evidence. Lancet. Oncol. 2011, 12, 477-488. [CrossRef]

176. Weischer, M.; Bojesen, S.E.; Ellervik, C.; Tybjaerg-Hansen, A.; Nordestgaard, B.G. CHEK2*1100delC genotyping for clinical assessment of breast cancer risk: Meta-analyses of 26,000 patient cases and 27,000 controls. J. Clin. Oncol. 2008, 26, 542-548. [CrossRef]

177. Johnson, N.; Fletcher, O.; Naceur-Lombardelli, C.; dos Santos Silva, I.; Ashworth, A.; Peto, J. Interaction between CHEK2*1100delC and other low-penetrance breast-cancer susceptibility genes: A familial study. Lancet 2005, 366, 1554-1557. [CrossRef]

178. Muranen, T.A.; Greco, D.; Blomqvist, C.; Aittomaki, K.; Khan, S.; Hogervorst, F.; Verhoef, S.; Pharoah, P.D.P.; Dunning, A.M.; Shah, M.; et al. Genetic modifiers of CHEK2*1100delC-associated breast cancer risk. Genet. Med. 2017, 19, 599-603. [CrossRef]

179. Lee, A.; Mavaddat, N.; Wilcox, A.N.; Cunningham, A.P.; Carver, T.; Hartley, S.; Babb de Villiers, C.; Izquierdo, A.; Simard, J.; Schmidt, M.K.; et al. BOADICEA: A comprehensive breast cancer risk prediction model incorporating genetic and nongenetic risk factors. Genet. Med. 2019, 21, 1708-1718. [CrossRef]

180. Gallagher, S.; Hughes, E.; Wagner, S.; Tshiaba, P.; Rosenthal, E.; Roa, B.B.; Kurian, A.W.; Domchek, S.M.; Garber, J.; Lancaster, J.; et al. Association of a Polygenic Risk Score With Breast Cancer Among Women Carriers of High- and Moderate-Risk Breast Cancer Genes. JAMA Netw. Open 2020, 3, e208501. [CrossRef]

181. Akdeniz, D.; Schmidt, M.K.; Seynaeve, C.M.; McCool, D.; Giardiello, D.; van den Broek, A.J.; Hauptmann, M.; Steyerberg, E.W.; Hooning, M.J. Risk factors for metachronous contralateral breast cancer: A systematic review and meta-analysis. Breast 2019, 44,1-14. [CrossRef]

182. Nizic-Kos, T.; Krajc, M.; Blatnik, A.; Stegel, V.; Skerl, P.; Novakovic, S.; Gazic, B.; Besic, N. Bilateral Disease Common among Slovenian CHEK2-Positive Breast Cancer Patients. Ann. Surg. Oncol. 2020. [CrossRef]

183. De Bock, G.H.; Schutte, M.; Krol-Warmerdam, E.M.; Seynaeve, C.; Blom, J.; Brekelmans, C.T.; Meijers-Heijboer, H.; van Asperen, C.J.; Cornelisse, C.J.; Devilee, P.; et al. Tumour characteristics and prognosis of breast cancer patients carrying the germline CHEK2*1100delC variant. J. Med. Genet. 2004, 41, 731-735. [CrossRef]

184. Meyer, A.; Dork, T.; Sohn, C.; Karstens, J.H.; Bremer, M. Breast cancer in patients carrying a germ-line CHEK2 mutation: Outcome after breast conserving surgery and adjuvant radiotherapy. Radiother. Oncol. J. 2007, 82, 349-353. [CrossRef]

185. Weischer, M.; Nordestgaard, B.G.; Pharoah, P.; Bolla, M.K.; Nevanlinna, H.; Van't Veer, L.J.; Garcia-Closas, M.; Hopper, J.L.; Hall, P.; Andrulis, I.L.; et al. CHEK2*1100delC heterozygosity in women with breast cancer associated with early death, breast cancer-specific death, and increased risk of a second breast cancer. J. Clin. Oncol. 2012, 30, 4308-4316. [CrossRef]

186. Kriege, M.; Hollestelle, A.; Jager, A.; Huijts, P.E.; Berns, E.M.; Sieuwerts, A.M.; Meijer-van Gelder, M.E.; Collee, J.M.; Devilee, P.; Hooning, M.J.; et al. Survival and contralateral breast cancer in CHEK2 1100delC breast cancer patients: Impact of adjuvant chemotherapy. Br. J. Cancer 2014, 111, 1004-1013. [CrossRef] 
187. Muranen, T.A.; Blomqvist, C.; Dork, T.; Jakubowska, A.; Heikkila, P.; Fagerholm, R.; Greco, D.; Aittomaki, K.; Bojesen, S.E.; Shah, M.; et al. Patient survival and tumor characteristics associated with CHEK2:p.I157T-findings from the Breast Cancer Association Consortium. Breast Cancer Res. 2016, 18, 98. [CrossRef]

188. De Bock, G.H.; Mourits, M.J.; Schutte, M.; Krol-Warmerdam, E.M.; Seynaeve, C.; Blom, J.; Brekelmans, C.T.; Meijers-Heijboer, H.; van Asperen, C.J.; Cornelisse, C.J.; et al. Association between the CHEK2*1100delC germ line mutation and estrogen receptor status. Int. J Gynecol. Cancer 2006, 16 (Suppl. 2), 552-555. [CrossRef]

189. Nagel, J.H.; Peeters, J.K.; Smid, M.; Sieuwerts, A.M.; Wasielewski, M.; de Weerd, V.; Trapman-Jansen, A.M.; van den Ouweland, A.; Bruggenwirth, H.; van, I.J.W.F.; et al. Gene expression profiling assigns CHEK2 1100delC breast cancers to the luminal intrinsic subtypes. Breast Cancer Res. Treat 2012, 132, 439-448. [CrossRef]

190. Couch, F.J.; Hart, S.N.; Sharma, P.; Toland, A.E.; Wang, X.; Miron, P.; Olson, J.E.; Godwin, A.K.; Pankratz, V.S.; Olswold, C.; et al. Inherited mutations in 17 breast cancer susceptibility genes among a large triple-negative breast cancer cohort unselected for family history of breast cancer. J. Clin. Oncol. 2015, 33, 304-311. [CrossRef]

191. Honrado, E.; Osorio, A.; Palacios, J.; Benitez, J. Pathology and gene expression of hereditary breast tumors associated with BRCA1, BRCA2 and CHEK2 gene mutations. Oncogene 2006, 25, 5837-5845. [CrossRef]

192. Kilpivaara, O.; Bartkova, J.; Eerola, H.; Syrjakoski, K.; Vahteristo, P.; Lukas, J.; Blomqvist, C.; Holli, K.; Heikkila, P.; Sauter, G.; et al. Correlation of CHEK2 protein expression and c.1100delC mutation status with tumor characteristics among unselected breast cancer patients. Int. J. Cancer 2005, 113, 575-580. [CrossRef]

193. Bahassi el, M.; Robbins, S.B.; Yin, M.; Boivin, G.P.; Kuiper, R.; van Steeg, H.; Stambrook, P.J. Mice with the CHEK2*1100delC SNP are predisposed to cancer with a strong gender bias. Proc. Natl. Acad. Sci. USA 2009, 106, 17111-17116. [CrossRef]

194. Huzarski, T.; Cybulski, C.; Domagala, W.; Gronwald, J.; Byrski, T.; Szwiec, M.; Woyke, S.; Narod, S.A.; Lubinski, J. Pathology of breast cancer in women with constitutional CHEK2 mutations. Breast Cancer Res. Treat. 2005, 90, 187-189. [CrossRef]

195. Angelova, S.G.; Krasteva, M.E.; Gospodinova, Z.I.; Georgieva, E.I. CHEK2 gene alterations independently increase the risk of death from breast cancer in Bulgarian patients. Neoplasma 2012, 59, 622-630. [CrossRef]

196. Boughey, J.C.; Attai, D.J.; Chen, S.L.; Cody, H.S.; Dietz, J.R.; Feldman, S.M.; Greenberg, C.C.; Kass, R.B.; Landercasper, J.; Lemaine, V.; et al. Contralateral Prophylactic Mastectomy Consensus Statement from the American Society of Breast Surgeons: Additional Considerations and a Framework for Shared Decision Making. Ann. Surg. Oncol. 2016, 23, 3106-3111. [CrossRef]

197. Wood, M.E.; McKinnon, W.; Garber, J. Risk for breast cancer and management of unaffected individuals with non-BRCA hereditary breast cancer. Breast J. 2020, 26, 1528-1534. [CrossRef]

198. Kukita, Y.; Okami, J.; Yoneda-Kato, N.; Nakamae, I.; Kawabata, T.; Higashiyama, M.; Kato, J.; Kodama, K.; Kato, K. Homozygous inactivation of CHEK2 is linked to a familial case of multiple primary lung cancer with accompanying cancers in other organs. Cold Spring Harb. Mol. Case Stud. 2016, 2, a001032. [CrossRef]

199. Van Puijenbroek, M.; van Asperen, C.J.; van Mil, A.; Devilee, P.; van Wezel, T.; Morreau, H. Homozygosity for a CHEK2*1100delC mutation identified in familial colorectal cancer does not lead to a severe clinical phenotype. J. Pathol. 2005, 206, 198-204. [CrossRef]

200. Dong, X.; Wang, L.; Taniguchi, K.; Wang, X.; Cunningham, J.M.; McDonnell, S.K.; Qian, C.; Marks, A.F.; Slager, S.L.; Peterson, B.J.; et al. Mutations in CHEK2 associated with prostate cancer risk. Am. J. Hum. Genet. 2003, 72, 270-280. [CrossRef]

201. Zhen, J.T.; Syed, J.; Nguyen, K.A.; Leapman, M.S.; Agarwal, N.; Brierley, K.; Llor, X.; Hofstatter, E.; Shuch, B. Genetic testing for hereditary prostate cancer: Current status and limitations. Cancer 2018. [CrossRef]

202. Brandão, A.; Paulo, P.; Maia, S.; Pinheiro, M.; Peixoto, A.; Cardoso, M.; Silva, M.P.; Santos, C.; Eeles, R.A.; Kote-Jarai, Z.; et al. The CHEK2 Variant C.349A>G Is Associated with Prostate Cancer Risk and Carriers Share a Common Ancestor. Cancers 2020, 12, 3254. [CrossRef]

203. Conti, D.V.; Wang, K.; Sheng, X.; Bensen, J.T.; Hazelett, D.J.; Cook, M.B.; Ingles, S.A.; Kittles, R.A.; Strom, S.S.; Rybicki, B.A.; et al. Two Novel Susceptibility Loci for Prostate Cancer in Men of African Ancestry. J. Natl. Cancer Inst. 2017, 109. [CrossRef]

204. Wang, Y.; Dai, B.; Ye, D. CHEK2 mutation and risk of prostate cancer: A systematic review and meta-analysis. Int. J. Clin. Exp. Med. 2015, 8, 15708-15715. 
205. Hale, V.; Weischer, M.; Park, J.Y. CHEK2 $\left(^{*}\right)$ 1100delC Mutation and Risk of Prostate Cancer. Prostate Cancer 2014, 2014, 294575. [CrossRef]

206. Cybulski, C.; Wokolorczyk, D.; Huzarski, T.; Byrski, T.; Gronwald, J.; Gorski, B.; Debniak, T.; Masojc, B.; Jakubowska, A.; Gliniewicz, B.; et al. A large germline deletion in the Chek2 kinase gene is associated with an increased risk of prostate cancer. J. Med. Genet. 2006, 43, 863-866. [CrossRef]

207. Seppala, E.H.; Ikonen, T.; Mononen, N.; Autio, V.; Rokman, A.; Matikainen, M.P.; Tammela, T.L.; Schleutker, J. CHEK2 variants associate with hereditary prostate cancer. Br. J. Cancer 2003, 89, 1966-1970. [CrossRef]

208. Abramson, J.H. WINPEPI updated: Computer programs for epidemiologists, and their teaching potential. Epidemiol. Perspect. Innov. Ep+I 2011, 8, 1. [CrossRef]

209. Isaacsson Velho, P.; Silberstein, J.L.; Markowski, M.C.; Luo, J.; Lotan, T.L.; Isaacs, W.B.; Antonarakis, E.S. Intraductal/ductal histology and lymphovascular invasion are associated with germline DNA-repair gene mutations in prostate cancer. Prostate 2018. [CrossRef]

210. Giri, V.N.; Hegarty, S.E.; Hyatt, C.; O’Leary, E.; Garcia, J.; Knudsen, K.E.; Kelly, W.K.; Gomella, L.G. Germline genetic testing for inherited prostate cancer in practice: Implications for genetic testing, precision therapy, and cascade testing. Prostate 2019, 79, 333-339. [CrossRef]

211. Wu, Y.; Yu, H.; Zheng, S.L.; Na, R.; Mamawala, M.; Landis, T.; Wiley, K.; Petkewicz, J.; Shah, S.; Shi, Z.; et al. A comprehensive evaluation of CHEK2 germline mutations in men with prostate cancer. Prostate 2018. [CrossRef]

212. Yadav, S.; Hu, C.; Hart, S.N.; Boddicker, N.; Polley, E.C.; Na, J.; Gnanaolivu, R.; Lee, K.Y.; Lindstrom, T.; Armasu, S.; et al. Evaluation of Germline Genetic Testing Criteria in a Hospital-Based Series of Women With Breast Cancer. J. Clin. Oncol. 2020, 38, 1409-1418. [CrossRef]

213. Cybulski, C.; Wokolorczyk, D.; Kluzniak, W.; Kashyap, A.; Golab, A.; Slojewski, M.; Sikorski, A.; Puszynski, M.; Soczawa, M.; Borkowski, T.; et al. A personalised approach to prostate cancer screening based on genotyping of risk founder alleles. Br. J. Cancer 2013, 108, 2601-2609. [CrossRef]

214. Zlowocka-Perlowska, E.; Narod, S.A.; Cybulski, C. CHEK2 Alleles Predispose to Renal Cancer in Poland. JAMA Oncol. 2019, 5, 576. [CrossRef]

215. Carlo, M.I.; Mukherjee, S.; Mandelker, D.; Vijai, J.; Kemel, Y.; Zhang, L.; Knezevic, A.; Patil, S.; Ceyhan-Birsoy, O.; Huang, K.C.; et al. Prevalence of Germline Mutations in Cancer Susceptibility Genes in Patients With Advanced Renal Cell Carcinoma. JAMA Oncol. 2018, 4, 1228-1235. [CrossRef]

216. Ge, Y.; Wang, Y.; Shao, W.; Jin, J.; Du, M.; Ma, G.; Chu, H.; Wang, M.; Zhang, Z. Rare variants in BRCA2 and CHEK2 are associated with the risk of urinary tract cancers. Sci. Rep. 2016, 6, 33542. [CrossRef]

217. Ged, Y.; Chaim, J.L.; DiNatale, R.G.; Knezevic, A.; Kotecha, R.R.; Carlo, M.I.; Lee, C.H.; Foster, A.; Feldman, D.R.; Teo, M.Y.; et al. DNA damage repair pathway alterations in metastatic clear cell renal cell carcinoma and implications on systemic therapy. J. Immunother. Cancer 2020, 8. [CrossRef]

218. Hartman, T.R.; Demidova, E.V.; Lesh, R.W.; Hoang, L.; Richardson, M.; Forman, A.; Kessler, L.; Speare, V.; Golemis, E.A.; Hall, M.J.; et al. Prevalence of pathogenic variants in DNA damage response and repair genes in patients undergoing cancer risk assessment and reporting a personal history of early-onset renal cancer. Sci. Rep. 2020, 10, 13518. [CrossRef]

219. Smith, P.S.; West, H.; Whitworth, J.; Castle, B.; Sansbury, F.H.; Warren, A.Y.; Woodward, E.R.; Tischkowitz, M.; Maher, E.R. Pathogenic germline variants in patients with features of hereditary renal cell carcinoma: Evidence for further locus heterogeneity. Genes Chromosomes Cancer 2020. [CrossRef]

220. Gadd, S.; Huff, V.; Walz, A.L.; Ooms, A.; Armstrong, A.E.; Gerhard, D.S.; Smith, M.A.; Auvil, J.M.G.; Meerzaman, D.; Chen, Q.R.; et al. A Children's Oncology Group and TARGET initiative exploring the genetic landscape of Wilms tumor. Nat. Genet. 2017, 49, 1487-1494. [CrossRef]

221. Ciceri, S.; Gamba, B.; Corbetta, P.; Mondini, P.; Terenziani, M.; Catania, S.; Nantron, M.; Bianchi, M.; D'Angelo, P.; Torri, F.; et al. Genetic and epigenetic analyses guided by high resolution whole-genome SNP array reveals a possible role of CHEK2 in Wilms tumour susceptibility. Oncotarget 2018, 9, 34079-34089. [CrossRef] [PubMed]

222. Kaczmarek-Rys, M.; Ziemnicka, K.; Hryhorowicz, S.T.; Gorczak, K.; Hoppe-Golebiewska, J.; Skrzypczak-Zielinska, M.; Tomys, M.; Golab, M.; Szkudlarek, M.; Budny, B.; et al. The c.470 T > C CHEK2 missense variant increases the risk of differentiated thyroid carcinoma in the Great Poland population. Hered. Cancer Clin. Pract. 2015, 13, 8. [CrossRef] [PubMed] 
223. Siolek, M.; Cybulski, C.; Gasior-Perczak, D.; Kowalik, A.; Kozak-Klonowska, B.; Kowalska, A.; Chlopek, M.; Kluzniak, W.; Wokolorczyk, D.; Palyga, I.; et al. CHEK2 mutations and the risk of papillary thyroid cancer. Int. J. Cancer 2015, 137, 548-552. [CrossRef] [PubMed]

224. Wojcicka, A.; Czetwertynska, M.; Swierniak, M.; Dlugosinska, J.; Maciag, M.; Czajka, A.; Dymecka, K.; Kubiak, A.; Kot, A.; Ploski, R.; et al. Variants in the ATM-CHEK2-BRCA1 axis determine genetic predisposition and clinical presentation of papillary thyroid carcinoma. Genes Chromosomes Cancer 2014, 53, 516-523. [CrossRef]

225. Pekova, B.; Dvorakova, S.; Sykorova, V.; Vacinova, G.; Vaclavikova, E.; Moravcova, J.; Katra, R.; Vlcek, P.; Sykorova, P.; Kodetova, D.; et al. Somatic genetic alterations in a large cohort of pediatric thyroid nodules. Endocr. Connect. 2019, 8, 796-805. [CrossRef]

226. Zhao, Y.; Yu, T.; Chen, L.; Xie, D.; Wang, F.; Fu, L.; Cheng, C.; Li, Y.; Zhu, X.; Miao, G. A Germline CHEK2 Mutation in a Family with Papillary Thyroid Cancer. Thyroid 2020, 30, 924-930. [CrossRef]

227. Cancer Genome Atlas Research, N. Integrated genomic characterization of papillary thyroid carcinoma. Cell 2014, 159, 676-690. [CrossRef]

228. Meijers-Heijboer, H.; Wijnen, J.; Vasen, H.; Wasielewski, M.; Wagner, A.; Hollestelle, A.; Elstrodt, F.; van den, B.R.; de Snoo, A.; Fat, G.T.; et al. The CHEK2 1100delC mutation identifies families with a hereditary breast and colorectal cancer phenotype. Am. J. Hum. Genet. 2003, 72, 1308-1314. [CrossRef]

229. Naseem, H.; Boylan, J.; Speake, D.; Leask, K.; Shenton, A.; Lalloo, F.; Hill, J.; Trump, D.; Evans, D.G. Inherited association of breast and colorectal cancer: Limited role of CHEK2 compared with high-penetrance genes. Clin. Genet. 2006, 70, 388-395. [CrossRef]

230. Katona, B.W.; Yang, Y.X. Colorectal cancer risk associated with the CHEK2 1100delC variant. Eur. J. Cancer 2017, 83, 103-105. [CrossRef]

231. Xiang, H.P.; Geng, X.P.; Ge, W.W.; Li, H. Meta-analysis of CHEK2 1100delC variant and colorectal cancer susceptibility. Eur. J. Cancer 2011, 47, 2546-2551. [CrossRef] [PubMed]

232. Ma, X.; Zhang, B.; Zheng, W. Genetic variants associated with colorectal cancer risk: Comprehensive research synopsis, meta-analysis, and epidemiological evidence. Gut 2014, 63, 326-336. [CrossRef] [PubMed]

233. Liu, C.; Wang, Q.S.; Wang, Y.J. The CHEK2 I157T variant and colorectal cancer susceptibility: A systematic review and meta-analysis. Asian Pac. J. Cancer Prev. 2012, 13, 2051-2055. [CrossRef] [PubMed]

234. Suchy, J.; Cybulski, C.; Wokolorczyk, D.; Oszurek, O.; Gorski, B.; Debniak, T.; Jakubowska, A.; Gronwald, J.; Huzarski, T.; Byrski, T.; et al. CHEK2 mutations and HNPCC-related colorectal cancer. Int. J. Cancer 2010, 126, 3005-3009. [CrossRef]

235. Kleibl, Z.; Havranek, O.; Hlavata, I.; Novotny, J.; Sevcik, J.; Pohlreich, P.; Soucek, P. The CHEK2 gene I157T mutation and other alterations in its proximity increase the risk of sporadic colorectal cancer in the Czech population. Eur. J. Cancer 2009, 45, 618-624. [CrossRef]

236. Cybulski, C.; Wokolorczyk, D.; Kladny, J.; Kurzawski, G.; Suchy, J.; Grabowska, E.; Gronwald, J.; Huzarski, T.; Byrski, T.; Gorski, B.; et al. Germline CHEK2 mutations and colorectal cancer risk: Different effects of a missense and truncating mutations? Eur. J. Hum. Genet. 2007, 15, 237-241. [CrossRef]

237. Djureinovic, T.; Lindblom, A.; Dalen, J.; Dedorson, S.; Edler, D.; Hjern, F.; Holm, J.; Lenander, C.; Lindforss, U.; Lundqvist, N.; et al. The CHEK2 1100delC variant in Swedish colorectal cancer. Anticancer Res. 2006, 26, 4885-4888.

238. Cragun, D.; Radford, C.; Dolinsky, J.S.; Caldwell, M.; Chao, E.; Pal, T. Panel-based testing for inherited colorectal cancer: A descriptive study of clinical testing performed by a US laboratory. Clin. Genet. 2014, 86, 510-520. [CrossRef]

239. Pearlman, R.; Frankel, W.L.; Swanson, B.; Zhao, W.; Yilmaz, A.; Miller, K.; Bacher, J.; Bigley, C.; Nelsen, L.; Goodfellow, P.J.; et al. Prevalence and Spectrum of Germline Cancer Susceptibility Gene Mutations Among Patients With Early-Onset Colorectal Cancer. JAMA Oncol. 2017, 3, 464-471. [CrossRef]

240. You, Y.N.; Borras, E.; Chang, K.; Price, B.A.; Mork, M.; Chang, G.J.; Rodriguez-Bigas, M.A.; Bednarski, B.K.; Meric-Bernstam, F.; Vilar, E. Detection of Pathogenic Germline Variants Among Patients With Advanced Colorectal Cancer Undergoing Tumor Genomic Profiling for Precision Medicine. Dis. Colon Rectum 2019, 62, 429-437. [CrossRef]

241. Rosenthal, E.T.; Evans, B.; Kidd, J.; Brown, K.; Gorringe, H.; van Orman, M.; Manley, S. Increased Identification of Candidates for High-Risk Breast Cancer Screening Through Expanded Genetic Testing. J. Am. Coll. Radiol. 2017, 14, 561-568. [CrossRef] 
242. Weischer, M.; Heerfordt, I.M.; Bojesen, S.E.; Eigentler, T.; Garbe, C.; Rocken, M.; Holmich, L.R.; Schmidt, H.; Klyver, H.; Bastholt, L.; et al. CHEK2*1100delC and risk of malignant melanoma: Danish and German studies and meta-analysis. J. Investig. Derm. 2012, 132, 299-303. [CrossRef]

243. Konstantinova, D.V.; Kadiyska, T.K.; Kaneva, R.P.; Tosheva, E.G.; Guseva, V.T.; Dimitrov, B.H.; Dimitrov, R.G.; Doganov, N.I.; Ivanov, S.I.; Kremensky, I.M.; et al. CHEK2 I157T and endometrial cancer. DNA Cell Biol. 2009, 28, 9-12. [CrossRef]

244. Ring, K.L.; Bruegl, A.S.; Allen, B.A.; Elkin, E.P.; Singh, N.; Hartman, A.R.; Daniels, M.S.; Broaddus, R.R. Germline multi-gene hereditary cancer panel testing in an unselected endometrial cancer cohort. Mod. Pathol. 2016, 29, 1381-1389. [CrossRef]

245. AlDubayan, S.H.; Pyle, L.C.; Gamulin, M.; Kulis, T.; Moore, N.D.; Taylor-Weiner, A.; Hamid, A.A.; Reardon, B.; Wubbenhorst, B.; Godse, R.; et al. Association of Inherited Pathogenic Variants in Checkpoint Kinase 2 (CHEK2) With Susceptibility to Testicular Germ Cell Tumors. JAMA Oncol. 2019. [CrossRef]

246. Bartsch, D.K.; Krysewski, K.; Sina-Frey, M.; Fendrich, V.; Rieder, H.; Langer, P.; Kress, R.; Schneider, M.; Hahn, S.A.; Slater, E.P. Low Frequency of CHEK2 Mutations in Familial Pancreatic Cancer. Fam. Cancer 2006, 5, 305-308. [CrossRef]

247. Mohelnikova-Duchonova, B.; Havranek, O.; Hlavata, I.; Foretova, L.; Kleibl, Z.; Pohlreich, P.; Soucek, P. CHEK2 gene alterations in the forkhead-associated domain, 1100delC and del5395 do not modify the risk of sporadic pancreatic cancer. Cancer Epidemiol. 2010, 34, 656-658. [CrossRef]

248. Obazee, O.; Archibugi, L.; Andriulli, A.; Soucek, P.; Malecka-Panas, E.; Ivanauskas, A.; Johnson, T.; Gazouli, M.; Pausch, T.; Lawlor, R.T.; et al. Germline BRCA2 K3326X and CHEK2 I157T mutations increase risk for sporadic pancreatic ductal adenocarcinoma. Int. J. Cancer 2019. [CrossRef]

249. Hu, C.; Hart, S.N.; Bamlet, W.R.; Moore, R.M.; Nandakumar, K.; Eckloff, B.W.; Lee, Y.K.; Petersen, G.M.; McWilliams, R.R.; Couch, F.J. Prevalence of Pathogenic Mutations in Cancer Predisposition Genes among Pancreatic Cancer Patients. Cancer Epidemiol. Biomark. Prev. 2016, 25, 207-211. [CrossRef]

250. Yurgelun, M.B.; Chittenden, A.B.; Morales-Oyarvide, V.; Rubinson, D.A.; Dunne, R.F.; Kozak, M.M.; Qian, Z.R.; Welch, M.W.; Brais, L.K.; Da Silva, A.; et al. Germline cancer susceptibility gene variants, somatic second hits, and survival outcomes in patients with resected pancreatic cancer. Genet. Med. 2019, 21, 213-223. [CrossRef]

251. Lovecek, M.; Janatova, M.; Skalicky, P.; Zemanek, T.; Havlik, R.; Ehrmann, J.; Strouhal, O.; Zemankova, P.; Lhotova, K.; Borecka, M.; et al. Genetic analysis of subsequent second primary malignant neoplasms in long-term pancreatic cancer survivors suggests new potential hereditary genetic alterations. Cancer Manag. Res. 2019, 11, 599-609. [CrossRef] [PubMed]

252. Pazderová, N.; Urbán, V.; Makovník, M.; Macák, D.; Janega, P.; Chovanec, M.; Rejleková, K.; Mardiak, J.; Mego, M. Complete Response to Chemotherapy in Metastatic Pancreatic Carcinoma Associated with Double Heterozygous Germline Mutation in BRCA2 and CHEK2 Genes-A Case Report. Klin. Onkol. 2020, 33, 220-225. [CrossRef] [PubMed]

253. Goldstein, J.B.; Zhao, L.; Wang, X.; Ghelman, Y.; Overman, M.J.; Javle, M.M.; Shroff, R.T.; Varadhachary, G.R.; Wolff, R.A.; McAllister, F.; et al. Germline DNA Sequencing Reveals Novel Mutations Predictive of Overall Survival in a Cohort of Patients with Pancreatic Cancer. Clin. Cancer Res. 2020, 26, 1385-1394. [CrossRef] [PubMed]

254. Wang, Y.; McKay, J.D.; Rafnar, T.; Wang, Z.; Timofeeva, M.N.; Broderick, P.; Zong, X.; Laplana, M.; Wei, Y.; Han, Y.; et al. Rare variants of large effect in BRCA2 and CHEK2 affect risk of lung cancer. Nat. Genet. 2014, 46, 736-741. [CrossRef]

255. Hangaishi, A.; Ogawa, S.; Qiao, Y.; Wang, L.; Hosoya, N.; Yuji, K.; Imai, Y.; Takeuchi, K.; Miyawaki, S.; Hirai, H. Mutations of Chk2 in primary hematopoietic neoplasms. Blood 2002, 99, 3075-3077. [CrossRef]

256. Rudd, M.F.; Sellick, G.S.; Webb, E.L.; Catovsky, D.; Houlston, R.S. Variants in the ATM-BRCA2-CHEK2 axis predispose to chronic lymphocytic leukemia. Blood 2006, 108, 638-644. [CrossRef]

257. Janiszewska, H.; Bak, A.; Pilarska, M.; Heise, M.; Junkiert-Czarnecka, A.; Kuliszkiewicz-Janus, M.; Calbecka, M.; Jazwiec, B.; Wolowiec, D.; Kuliczkowski, K.; et al. A risk of essential thrombocythemia in carriers of constitutional CHEK2 gene mutations. Haematologica 2012, 97, 366-370. [CrossRef]

258. Havranek, O.; Kleiblova, P.; Hojny, J.; Lhota, F.; Soucek, P.; Trneny, M.; Kleibl, Z. Association of Germline CHEK2 Gene Variants with Risk and Prognosis of Non-Hodgkin Lymphoma. PLoS ONE 2015, 10, e0140819. [CrossRef] 
259. Havranek, O.; Spacek, M.; Hubacek, P.; Mocikova, H.; Markova, J.; Trneny, M.; Kleibl, Z. Alterations of CHEK2 forkhead-associated domain increase the risk of Hodgkin lymphoma. Neoplasma 2011, 58, 392-395. [CrossRef]

260. Szymanska-Pasternak, J.; Szymanska, A.; Medrek, K.; Imyanitov, E.N.; Cybulski, C.; Gorski, B.; Magnowski, P.; Dziuba, I.; Gugala, K.; Debniak, B.; et al. CHEK2 variants predispose to benign, borderline and low-grade invasive ovarian tumors. Gynecol. Oncol. 2006, 102, 429-431. [CrossRef]

261. Lilyquist, J.; LaDuca, H.; Polley, E.; Davis, B.T.; Shimelis, H.; Hu, C.; Hart, S.N.; Dolinsky, J.S.; Couch, F.J.; Goldgar, D.E. Frequency of mutations in a large series of clinically ascertained ovarian cancer cases tested on multi-gene panels compared to reference controls. Gynecol. Oncol. 2017, 147, 375-380. [CrossRef] [PubMed]

262. Carter, N.J.; Marshall, M.L.; Susswein, L.R.; Zorn, K.K.; Hiraki, S.; Arvai, K.J.; Torene, R.I.; McGill, A.K.; Yackowski, L.; Murphy, P.D.; et al. Germline pathogenic variants identified in women with ovarian tumors. Gynecol. Oncol. 2018, 151, 481-488. [CrossRef] [PubMed]

263. Koczkowska, M.; Krawczynska, N.; Stukan, M.; Kuzniacka, A.; Brozek, I.; Sniadecki, M.; Debniak, J.; Wydra, D.; Biernat, W.; Kozlowski, P.; et al. Spectrum and Prevalence of Pathogenic Variants in Ovarian Cancer Susceptibility Genes in a Group of 333 Patients. Cancers 2018, 10, 442. [CrossRef] [PubMed]

Publisher's Note: MDPI stays neutral with regard to jurisdictional claims in published maps and institutional affiliations.

(C) 2020 by the authors. Licensee MDPI, Basel, Switzerland. This article is an open access article distributed under the terms and conditions of the Creative Commons Attribution (CC BY) license (http://creativecommons.org/licenses/by/4.0/). 